\title{
Simultaneous retrieval of aerosol and surface optical properties from combined airborne- and ground-based direct and diffuse radiometric measurements
}

\author{
C. K. Gatebe ${ }^{1,2}$, O. Dubovik ${ }^{3}$, M. D. King ${ }^{2,4}$, and A. Sinyuk ${ }^{2,5}$ \\ ${ }^{1}$ Goddard Earth Sciences and Technology Center, University of Maryland, Baltimore County, Baltimore, \\ Maryland 21228, USA \\ ${ }^{2}$ NASA Goddard Space Flight Center, Greenbelt, Maryland 20771, USA \\ ${ }^{3}$ Laboratoire d'Optique Atmospherique, Centre National de la Research Scientifique et Université des Sciences et \\ Technologies de Lille, 59655 Villeneuve d'Ascq, France \\ ${ }^{4}$ Laboratory for Atmospheric and Space Physics, University of Colorado, Boulder, Colorado, 80309-0392, USA \\ ${ }^{5}$ Sigma Space Corp., Lanham, MD, 20706, USA
}

Received: 20 October 2009 - Published in Atmos. Chem. Phys. Discuss.: 10 December 2009

Revised: 13 March 2010 - Accepted: 15 March 2010 - Published: 25 March 2010

\begin{abstract}
This paper presents a new method for simultaneously retrieving aerosol and surface reflectance properties from combined airborne and ground-based direct and diffuse radiometric measurements. The method is based on the standard Aerosol Robotic Network (AERONET) method for retrieving aerosol size distribution, complex index of refraction, and single scattering albedo, but modified to retrieve aerosol properties in two layers, below and above the aircraft, and parameters on surface optical properties from combined datasets (Cloud Absorption Radiometer (CAR) and AERONET data). A key advantage of this method is the inversion of all available spectral and angular data at the same time, while accounting for the influence of noise in the inversion procedure using statistical optimization. The wide spectral $(0.34-2.30 \mu \mathrm{m})$ and angular range $\left(180^{\circ}\right)$ of the CAR instrument, combined with observations from an AERONET sunphotometer, provide sufficient measurement constraints for characterizing aerosol and surface properties with minimal assumptions. The robustness of the method was tested on observations made during four different field campaigns: (a) the Southern African Regional Science Initiative 2000 over Mongu, Zambia, (b) the Intercontinental Transport Experiment-Phase B over Mexico City, Mexico (c) Cloud and Land Surface Interaction Campaign over the Atmospheric Radiation Measurement (ARM) Central Facility, Oklahoma, USA, and (d) the Arctic Research of the Compo-
\end{abstract}

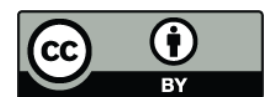

Correspondence to: C. K. Gatebe (charles.k.gatebe@nasa.gov) sition of the Troposphere from Aircraft and Satellites (ARCTAS) over Elson Lagoon in Barrow, Alaska, USA. The four areas are dominated by different surface characteristics and aerosol types, and therefore provide good test cases for the new inversion method.

\section{Introduction}

The techniques for deriving atmospheric aerosols from solar transmission measurements may be traced back to the very early effort of Bouguer in 1725 on measuring light extinction at different solar elevations in an attempt to discover "a true law" followed by light in its attenuation (cf. Bouguer, 1760). However, it wasn't until 1760, two years after Bouguer's death, that the exponential decrement of radiation in a media was formulated mathematically by Johann Heinrich Lambert, using Bouguer's 1725 measurements (cf. Lambert, 1760). Arguably, the two pioneered what is referred to today as remote sensing of atmospheric aerosols.

While the atmosphere may have been cleaner during Bouguer or Lambert's time, the emergence of the Industrial Revolution is believed to have set about environmental degradation in significant ways. For example, the disappearance of fresh air and blue skies, particularly in and around industrial cities, started to become evident and widespread in many areas of Europe. At the same time, atmospheric turbidity measurements grew from subjective comparative measurements made with the eye (Bouguer, 1760) to photographic methods (measurements of total intensity of white light

Published by Copernicus Publications on behalf of the European Geosciences Union. 
affecting photographic compounds after passing through various air thicknesses; e.g. Abney, 1893), to electrical readout following the development of electrical thermopile detectors (e.g., Abbot, 1913), to handheld analog instruments (e.g., Voltz, 1959) and the modern digital units of laboratory quality (e.g., Holben et al., 1998). Airborne and satellite instruments have now become viable platforms for making environmental measurements such as aerosol properties as described in detail by King et al. (1999).

Radiation scattered by the atmosphere and reflected by clouds and the Earth's surface features can be used to derive aerosols, clouds, and surface optical and microphysical properties. In the case of aerosols, one of the main challenges facing retrievals, especially from airborne or satellite observations, is separation of contributions from the surface and the atmosphere in a cloud-free environment. A number of methods have been developed for retrieving aerosols from satellite measurements with some degree of success, albeit confined to areas of low surface reflectance, especially over oceans (cf. Griggs, 1975; Tanré et al., 1997), or over landscapes that are relatively dark in the near-infrared (Kaufman et al., 1997) or in the UV bands (Herman et al., 1997). There are a few methods that are used to retrieve aerosol properties over bright surfaces such as arid or unvegetated surfaces by making use of multi-channel, multi-angle, and/or polarimetric satellite observations (cf. Hsu et al., 2004; Diner et al., 2008; Deuzé et al., 1993). But none of these methods have the ability to retrieve complete sets of aerosol optical properties, and most derive only the total aerosol content assuming aerosol models representative of local conditions.

In this study, we present a new method for retrieving simultaneously aerosol and bidirectional reflectance distribution function parameters from combined airborne and ground-based direct and diffuse radiometric measurements. Our method is based on the Dubovik and King (2000) inversion method, which is now the standard method used in the Aerosol Robotic Network (AERONET) project for retrieving aerosol size distribution, complex index of refraction, and single scattering albedo. The following section, Sect. 2, describes the basic principles used in deducing atmospheric characteristics of aerosols, especially aerosol optical thickness and aerosol size distribution. Section 3 describes data and measurements used in the inversion. Section 4 describes results of the inversion and Sect. 5, the last section, contains a summary and conclusions.

\section{Theory and methods}

In this section, we review some of the principles and theories used in derivation of aerosol characteristics from directly transmitted solar radiation or a combination of directly transmitted and scattered solar radiation, focusing on retrieving parameters of aerosol microstructure, such as particle size and number concentration. While this information is not new, Sects. 2.1 and 2.2 provide good background knowledge on the new inversion algorithm as discussed in Sect. 2.3.

\subsection{Retrieval of aerosol optical thickness}

The simplest method used for inferring aerosol characteristics from solar measurements is based on Bouguer's law. This law appears in the literature with different names such as Bouguer-Langley method (Deirmendjian and Sekera, 1956), Beer's Law (Herman and Yarger 1966), Lambert-Beer law (Shaw et al., 1973), or Beer-Lambert-Bouguer law (Holben et al., 1998), or Transmission law or Bouguer's law (c.f. Ångström, 1961; Deepak and Box, 1978; Shaw, 1983; Bodhaine et al., 1999; Siegel and Howell, 2002), and Extinction law (Thomas and Stamnes, 1999). This can be confusing, but it is worthwhile noting that Bouguer was the first to show that in a medium of uniform transparency, light remaining in a collimated beam is an exponential function of its path in the medium (Bouguer, 1760).

Bouguer's law assumes that radiation transmitted directly through the atmosphere depends only on the density of the atmosphere and solar zenith distance. In a mathematical sense this relation can be expressed as:

$F\left(\lambda, \theta_{0}\right)=F_{0}(\lambda) \exp \left(-m\left(\theta_{0}\right) \tau_{t}(\lambda)\right)$,

where $F\left(\lambda, \theta_{0}\right)$ is the solar flux measured at a wavelength $\lambda$ and solar zenith angular distance $\theta_{0}$, and $F_{0}$ is the spectral solar flux observed at the top of the atmosphere or at zero air mass. The term $m\left(\theta_{0}\right)$ is the atmospheric air mass relative to the vertical direction, which is approximated by $\sec \left(\theta_{0}\right)$ for $\theta_{0} \leq 80^{\circ}$. There is a need to take into account the curvature of atmospheric layers and refraction effects due to variations in atmospheric densities for $\theta_{0}>80^{\circ}$. The term $\tau_{t}$ is the total spectral optical thickness along the local zenith. When $\tau_{t}>0.5$, contribution from diffusely scattered flux is significant and should be taken into account (Herman et al., 1971). The logarithmic form of Eq. (1) is given by:

$\ln F\left(\lambda, \theta_{0}\right)=-m\left(\theta_{0}\right) \tau_{t}(\lambda)+\ln F_{0}(\lambda)$.

A plot of $\ln F\left(\lambda, \theta_{0}\right)$ against $m\left(\theta_{0}\right)$ yields a linear curve of slope $-\tau_{t}$, provided that $\tau_{t}$ remains constant during measurements. Equation (2) is sometimes expressed in terms of voltages $V\left(\lambda, \theta_{0}\right)$ or instrument digital count $\mathrm{DN}\left(\lambda, \theta_{0}\right)$, both of which are linearly related to $F\left(\lambda, \theta_{0}\right)$. If an absolute calibration of the radiometer is required in terms of signal per unit of incident radiant flux, the linear fit has to be extrapolated to $m\left(\theta_{0}\right)=0.0$, and then compared to known values of incident solar radiation at zero airmass or at the top of the atmosphere (Shaw et al., 1973).

The spectral aerosol optical thickness, $\tau_{a}$, is derived from the total spectral optical thickness, $\tau_{t}$ by first calculating the optical thickness due to scattering by air molecules, the Rayleigh optical thickness, $\tau_{R}$, and the optical thickness due 
to gas absorption, $\tau_{g}$, (e.g., ozone, water vapor, carbon dioxide and oxygen) and then subtracting these components from $\tau_{t}$. This can be formulated mathematically as:

$\tau_{a}(\lambda)=\tau_{t}(\lambda)-\tau_{R}(\lambda)-\tau_{g}(\lambda)$

Equation (3) applies to measurements made at sea level, but can be applied to measurements at any other altitude, provided that $\tau_{R}$ is multiplied by a ratio between atmospheric pressure at any altitude and sea level for a standard atmosphere. The term $\tau_{g}$ can be minimized or completely eliminated by selecting measurements located in regions of the solar spectrum with few or no gaseous absorption features and maximum transmission. Equations (2) and (3) provide relationships that enable derivation of spectral aerosol optical thickness from direct solar spectral measurements (Holben et al., 1998; Russell et al., 1999).

In the next subsections, we will show that aerosol size distribution can be derived from aerosol optical thickness and diffuse radiance of the sky.

\subsection{Retrieval of aerosol size distribution}

The dependence of aerosol extinction on the size of atmospheric aerosol particles was originally demonstrated by Ångström (1929). Later studies demonstrated new techniques for deriving aerosol particle size distribution (e.g., Yamamoto and Tanaka, 1969; King et al., 1978). The mathematical expression relating aerosol optical thickness $\tau_{a}$ at any height $h$ to aerosol particle size distribution can be written in the form:

$\tau_{a}(\lambda)=\int_{0}^{\infty} \int_{0}^{\infty} \pi r^{2} Q(\lambda, r, m) n(r, h) d r d h$,

where $n(r, h) d r$ represents number of particles within the radius interval $[r, r+d r]$ at height $h, Q(\lambda, r, m)$ is the extinction efficiency factor from Mie theory for a spherical particle of radius $r$ and index of refraction $m$ illuminated by radiation of wavelength $\lambda$. By integrating Eq. (4) over the whole atmospheric column, we get:

$\tau_{a}(\lambda)=\int_{0}^{\infty} \pi r^{2} Q(\lambda, r, m) N(r) d r$,

where $N(\mathrm{r})$ represents the number of particles within the interval $[r, r+\mathrm{d} r]$ in a vertical column through the atmosphere. It is difficult to estimate the weighting function $\pi r^{2} Q(\lambda, r$, $m)$ at all wavelengths when $r$ becomes large. This is resolved through the use of a surface size distribution of the particles $\left(s(r)=\pi r^{2} N(\lambda, r, m)\right)$ instead of $N(r)$ or, better still use the volume size distribution, which commands the total amount of particulate matter $\left(v(r)=\frac{4}{3} \pi r^{3} N(\lambda, r, m)\right)$. The problem is then to determine $N(r)$ (or better $s(r)$ or $v(r)$ ) from Eq. (5) for a given $\tau_{a}(\lambda)$ and kernel function $Q(\lambda, r, m)$. This equation is an example of a Fredholm integral equation of the first kind, which is notoriously difficult to solve, especially when the kernel function overlaps or is dependent at different wavelengths. This problem can be solved using the inversion technique suggested by Phillips (1961) and modified by Twomey (1963). Since $\tau_{a}$ is not known accurately, Eq. (5) can be rewritten in the form:

$\int_{r^{1}}^{r^{2}} \pi r^{2} Q(\lambda, r, m) N(r) d r=\tau_{a}(\lambda)+\varepsilon(\lambda)$,

where $\varepsilon(\lambda)$ is an error in $\tau_{a}(\lambda)$. The introduction of an error term, which is independent of $N(r)$, and by extension $\tau_{a}$, helps to ensure that the solution does not oscillate and converges to a point. This leads to a solution of the form:

$\boldsymbol{f}=\left(\mathbf{A}^{T} \mathbf{C}^{-1} \mathbf{A}+\gamma \mathbf{H}\right)^{-1} \mathbf{A}^{T} \mathbf{C}^{-1} \boldsymbol{g}$,

where $f=N\left(r_{j}\right), \mathbf{A}=\int_{r_{\mathrm{j}}}^{r_{\mathrm{j}}+1} \pi r^{2} Q(\lambda, r, m) d r, \mathbf{A}^{T}$ is the transpose of $\mathbf{A}, \mathbf{C}$ is the measurement covariance matrix, $\boldsymbol{g}=$ $\tau_{a}(\lambda), \mathbf{H}$ is a smoothing matrix and $\gamma$ is some non-negative Lagrange multiplier (King et al., 1978; King, 1982). Therefore, from the spectral aerosol optical thickness measurements, we can infer information about aerosol microstructure such as particle size and number distribution.

So far we have discussed the inverse problem of determining the size distribution of spherical polydispersions from solar spectral extinction measurements, which requires measurements of directly transmitted radiation. Nakajima et al. $(1983,1996)$ describe the retrieval of aerosol size distribution from angular dependence of diffuse radiation in the solar aureole. The aureole observations are affected by multiple light scattering in the atmosphere and, in contrast to Eq. (6), the measurements depend on aerosol size distribution nonlinearly. Correspondingly, the solution is obtained iteratively where correction to the solution at each iteration is determined by solving a linear system of equations rather similar to the one of Eq. (7).

\subsection{Inversion of aerosol and surface optical characteristics}

Our inversion algorithm is based on the Dubovik and King (2000) inversion method, which is now the standard method used in the Aerosol Robotic Network (AERONET) project. In contrast to the methods discussed above, the Dubovik and King (2000) algorithm derives simultaneously several characteristics of aerosol, including size distribution and spectrally dependent real and complex part of the refractive index, from ground-based measurements of both direct spectral and diffuse angular atmospheric radiation. The algorithm rigorously implements statistical optimization of the solution and uses several different a priori constraints. 
In our studies, the Dubovik and King (2000) algorithm was modified in order to retrieve an expanded set of aerosol parameters together with the surface properties from a combined dataset of coincident CAR and AERONET observations. In the following sections, we will describe the mathematical basis of the joint inversion scheme, starting with the AERONET inversion scheme.

\subsubsection{Overview of AERONET retrieval}

Formally, the retrieval algorithm is designed as a multiterm LSM (Least Square Method) (see detailed discussion by Dubovik, 2004) that implements statistically optimum fitting of several sets of observations and a priori constraints under assumption of normally distributed uncertainties. The AERONET retrieval is designed as a solution for the following system of equations:

$$
\left\{\begin{array}{c}
f^{*}=f(a)+\Delta \mathbf{f}^{*} \\
0^{*}=\operatorname{Sa}+\Delta(\Delta \boldsymbol{a})
\end{array}\right.
$$

Here, the first system is related to AERONET observations: $f^{*}$ the vector of measurements that include the logarithms of the measured values of the spectral optical thickness and spectral-angular sky-radiances, and $\Delta \boldsymbol{f}^{*}$ the vector of measurement uncertainties. The vector of unknowns (see Dubovik and King, 2000) $\boldsymbol{a}$ includes the logarithms of the parameters characterizing aerosol properties in the total atmospheric column: 22 values of size distribution $d V\left(r_{i}\right) / d \ln r$, four values of spectral real $n\left(\lambda_{i}\right)$ and complex $k\left(\lambda_{i}\right)$ refractive indices (i=4), and the fraction of spherical particles $C_{S} / n_{s}$. (The possibility of retrieving $C_{S} / n_{s}$ was added in studies described by Dubovik et al., 2006). Correspondingly, the AERONET retrieval is driven by 31 unknowns (22 size distribution variables for $r=0.05-15 \mu \mathrm{m}, 4$ spectral variables for real index of refraction, 4 spectral variables for imaginary index of refraction, where $\lambda=0.44,0.67,0.87$, and $1.02 \mu \mathrm{m}$, and 1 variable for the fraction of spherical particles).

In order to account for the non-negative character of the characteristics, and to use the assumption of log-normal error distribution that is the most appropriate for the positivelydefined values, the logarithmic transformation is used for both measured $f_{j}$ and retrieved $a_{i}$ parameters (see detailed discussion in the paper by Dubovik and King, 2000). Correspondingly, the errors $\Delta \boldsymbol{f}^{*}$ are assumed normally distributed. The second system in Eq. (8) is related to the a priori smoothness assumptions used to constrain variability of size distribution and spectral dependencies of real and complex refractive indices. The matrix $\mathbf{S}$ includes the coefficients for calculating $m$-differences (numerical equivalent of the derivatives) of $d V\left(r_{j}\right) / d \ln r, n\left(\lambda_{j}\right)$ and $k\left(\lambda_{j}\right) ; \boldsymbol{O}^{*}$ the vector of zeros and $\Delta(\Delta \boldsymbol{a})$ is the vector of uncertainties characterizing the deviations of the differences from the zeros. Formally, this equation states that the $m$-th differences of $d V\left(r_{j}\right) / d \ln r, n\left(\lambda_{j}\right)$ and $k\left(\lambda_{j}\right)$ are equal to zeros $\boldsymbol{0}^{*}$ with the uncertainties $\Delta\left(\Delta^{m} \boldsymbol{a}\right)$. Since the a priori smoothness con- straints are applied in AERONET on several different aerosol characteristics, the matrix $\mathbf{S}$ has the following array structure:

$\mathbf{S} \boldsymbol{a}=\left(\begin{array}{cccc}\mathbf{S}_{v} & 0 & 0 & 0 \\ 0 & \mathbf{S}_{n} & 0 & 0 \\ 0 & 0 & \mathbf{S}_{k} & 0 \\ 0 & 0 & 0 & 0\end{array}\right)\left(\begin{array}{c}\boldsymbol{a}_{v} \\ \boldsymbol{a}_{n} \\ \boldsymbol{a}_{k} \\ \boldsymbol{a}_{c}\end{array}\right)$,

where $a_{v}, a_{n}, a_{k}$ and $a_{c}$ denote the components of the vector $\boldsymbol{a}$ corresponding to $d V(r) / d \ln r, n(\lambda), k(\lambda)$ and $C_{s} / n_{s}$. The correspondent matrices $\mathbf{S}$... have different dimensions and represent differences of different order ( 3 for size distribution, 1 for $n(\lambda)$ and 2 for $k(\lambda))$.

The solution of Eq. (8) is obtained by the following iterative procedure:

$\boldsymbol{a}^{p+1}=\boldsymbol{a}^{p}-\Delta \boldsymbol{a}^{p}$

$\Delta \boldsymbol{a}^{p}$

$=\left(\mathbf{K}_{p}^{\mathrm{T}} \mathbf{W}^{-1} \mathbf{K}_{p}+\gamma \Omega\right)^{-1}\left(\mathbf{K}_{p}^{\mathrm{T}} \mathbf{W}^{-1} \Delta \boldsymbol{f}^{p}+\gamma \Omega \boldsymbol{a}^{p}\right)$,

where $\Delta \boldsymbol{f}^{p}=\boldsymbol{f}\left(\boldsymbol{a}^{p}\right)-\boldsymbol{f}^{*}, \Omega=\mathbf{S}^{\mathrm{T}} \mathbf{S}$ is the smoothness matrix, $\mathbf{K}_{p}$ the Jacobi matrix of the first derivatives $\frac{\partial f_{j}\left(\boldsymbol{a}^{p}\right)}{\partial a_{i}}$, and $\mathbf{W}$ the measurement weighting matrix defined by normalizing the measurement covariance matrix $\mathbf{C}_{f}$ by its first diagonal element $\varepsilon_{f}^{2}$, i.e., $\mathbf{W}=\left(1 / \varepsilon_{f}^{2}\right) \mathbf{C}_{f}$. The Lagrange multiplier $\gamma$ characterizes the contribution of the a priori term into the solution that can be defined (see Dubovik and King, 2000) as the ratio of $\varepsilon_{f}^{2}$ to $\varepsilon_{\Delta}^{2}$ (variance of $\Delta\left(\Delta^{m} \boldsymbol{a}\right)$ deviations): $\gamma=\varepsilon_{f}^{2} / \varepsilon_{\Delta}^{2}$. Correspondingly, if the uncertainty $\varepsilon_{\Delta}^{2}$ is very large, the a priori term in Eq. (10) vanishes. The covariance matrix of the retrieval errors can be estimated as:

$\left\langle\Delta \widehat{\boldsymbol{a}}(\Delta \widehat{\boldsymbol{a}})^{\mathrm{T}}\right\rangle=\left(\mathbf{K}_{p}^{\mathrm{T}} \mathbf{W}^{-1} \mathbf{K}_{p}+\gamma \Omega\right)^{-1} \varepsilon_{f}^{2}$,

where $p$ corresponds to the number of the last iteration and $\widehat{\boldsymbol{a}}=\boldsymbol{a}^{p}$ is the final solution.

The iterations of Eq. (10) minimize the following quadratic form:

$\Psi(\boldsymbol{a})=\frac{1}{2}\left(\Delta \boldsymbol{f}^{T}(\mathbf{W})^{-1} \Delta \boldsymbol{f}+\gamma \boldsymbol{a}^{p} \Omega \boldsymbol{a}^{p}\right)$.

If all the assumptions are correct the minimum value of the above quadratic form can be estimated as follows:

$\Psi(\boldsymbol{a})=\left(N_{f}-N_{a}\right) \varepsilon_{f}^{2}$,

where $N_{f}$ denotes the total number of measurements, including the number of a priori relationships, that are formally considered by the inversion approach, and $N_{a}$ denotes the total number of retrieved parameters. Once the value of the measurement error $\varepsilon_{f}$ is known, Eq. (12) can be used to verify the consistency of the retrieval. Specifically, the inability to achieve the above minimum can indicate the presence of unidentified biases or inadequacy in the assumptions made. 


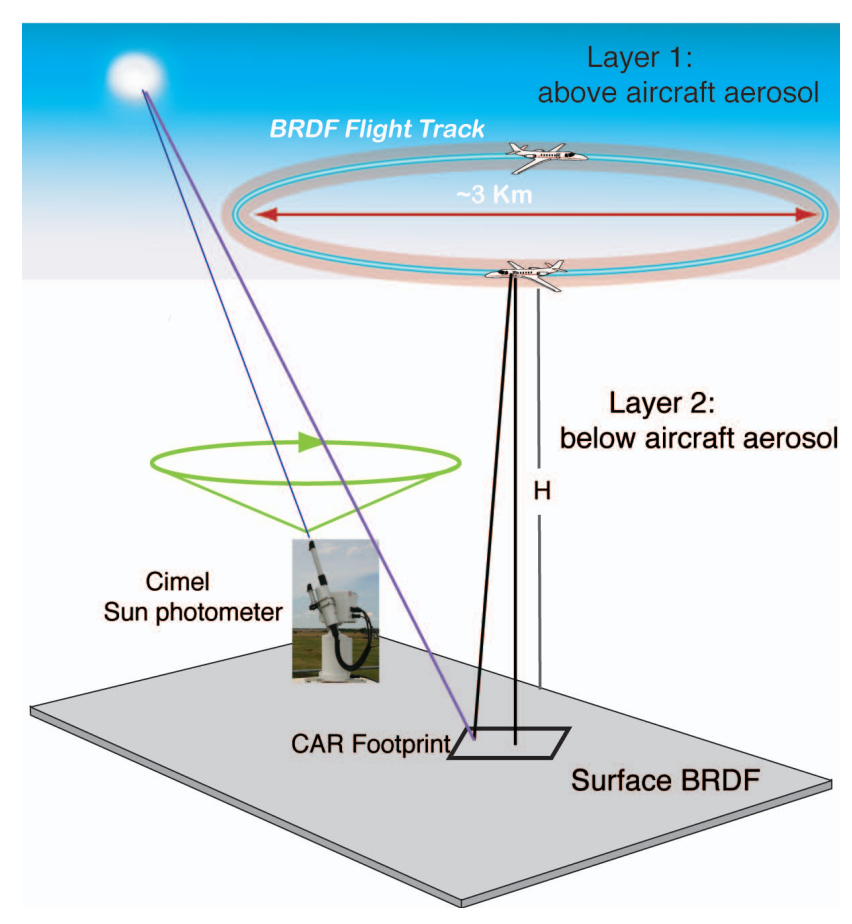

Fig. 1. Measurement configuration for joint CAR-sunphotometer inversion. $\mathrm{H}$ is the aircraft height above the ground target, normally $\sim 600 \mathrm{~m}$. The combination of CAR and AERONET data provides more detailed information about the distribution of atmospheric radiation than AERONET observations alone, and allow retrieval of aerosol above and below aircraft and surface BRDF.

\subsubsection{Joint inversion of CAR/AERONET data}

The combination of CAR and AERONET data provides more detailed information about the distribution of atmospheric radiation than AERONET observations alone, and hence a number of important additions to the inverse algorithm by Dubovik and King (2000) were adopted that extended the AERONET retrieval algorithm to inverting the CAR/AERONET joint dataset.

CAR observations provide measurements of both upwelling and downwelling radiation over the AERONET site (Figs. 1 and 2). These observations have significantly different sensitivities compared to AERONET data. First, the measurements of the upwelling radiation are very sensitive to the detailed properties of the surface reflectance. Second, CAR observations of downwelling radiation are sensitive mostly to aerosol properties above the plane. Correspondingly, the inversion concept considering the columnar values of atmospheric aerosol size distribution and complex refractive index as the only groups of the retrieved parameters (surface reflectance and vertical distribution of aerosol were assumed) needs to be adjusted. Indeed, this inversion concept is justified by the low sensitivity of AERONET data to surface reflectance and aerosol vertical variability that is hardly applicable to interpretation of joint sets of CAR/AERONET observations. As a result, retrieval of aerosol from a joint CAR/AERONET dataset needs to deal with a significantly larger number of measurements and retrieved parameters. Nonetheless, thanks to the flexible concept of the multi-term LSM suggested by Dubovik and King (2000) and Dubovik (2004), the general structure of the retrieval remains formally the same. Therefore, the inversion of joint CAR/AERONET data can be implemented following the same Eqs. (8-12) with only a few adjustments related to the interpretation of the employed matrices and vectors.

As illustrated in Fig. 1, we have modified the vector of the retrieved parameters separating the properties of aerosol above $\left(\boldsymbol{a}_{\text {above }}\right)$ and below $\left(\boldsymbol{a}_{\text {below }}\right)$ the plane and adding the parameters $\left(\boldsymbol{a}_{\text {brdf }}\right)$ of the surface BRDF (bidirectional reflectance):

$\boldsymbol{a}=\left(\begin{array}{c}\boldsymbol{a}_{\text {above }} \\ \boldsymbol{a}_{\text {below }} \\ \boldsymbol{a}_{\text {brdf }}\end{array}\right)$,

where the vectors $\boldsymbol{a}_{\text {above }}$ and $\boldsymbol{a}_{\text {below }}$ have the same structure as the vector $\boldsymbol{a}$ in Eq. (9) with the only difference being that they characterize the columnar aerosol properties (size distribution $d V(r) / d \ln r$, spectral real $n(\lambda)$ and complex $k(\lambda)$ refractive indices, fraction of spherical particles $C_{s /} n_{s}$ ) above and below the plane, while the vector $\boldsymbol{a}$ was formulated for the entire atmosphere. The vector $\boldsymbol{a}_{\text {brdf }}$ includes BRDF model parameters (e.g., the three parameters of the CSAR model, discussed later in Sect. 4.2.3, and whose parameters are specified by $\boldsymbol{a}_{\text {brdf, } 1}, \boldsymbol{a}_{\mathrm{brdf}, 2}$ and $\boldsymbol{a}_{\mathrm{brdf}, 3}$ that are related to the spectrally dependent parameters $\rho_{0}(\lambda), k(\lambda)$ and $\Theta(\lambda)$ of our employed BRDF model). Correspondingly, the components of vector $\boldsymbol{a}$ in Eq. (9) have the following detailed structure:

$\boldsymbol{a}_{\mathrm{above}}=\left(\begin{array}{c}\boldsymbol{a}_{v} \\ \boldsymbol{a}_{n} \\ \boldsymbol{a}_{k} \\ a_{c}\end{array}\right)_{\text {above }}, \quad \boldsymbol{a}_{\text {below }}=\left(\begin{array}{c}\boldsymbol{a}_{v} \\ \boldsymbol{a}_{n} \\ \boldsymbol{a}_{k} \\ a_{c}\end{array}\right)_{\text {below }}$,

and $\boldsymbol{a}_{\mathrm{brdf}}=\left(\begin{array}{c}\boldsymbol{a}_{\mathrm{brdf}, 1} \\ \boldsymbol{a}_{\mathrm{brdf}, 2} \\ \boldsymbol{a}_{\mathrm{brdf}, 3}\end{array}\right)$

The a priori constraints shown by the second line in Eq. (8) should be adjusted correspondingly. Namely, we use similar smoothness constraints for $\boldsymbol{a}_{\text {above }}$ and $\boldsymbol{a}_{\text {below }}$, which have the same structure as the vector $\boldsymbol{a}$ in Eq. (9). In addition, following the studies by Sinyuk et al. (2007), we have applied some a priori constraints on the spectral variability of BRDF parameters. Then, the matrix $\mathbf{S}$ in Eq. (8) will have the following array structure:

$\mathbf{S} \boldsymbol{a}=\left(\begin{array}{ccc}\mathbf{S}_{\mathrm{aer}} & 0 & 0 \\ 0 & \mathbf{S}_{\mathrm{arr}} & 0 \\ 0 & 0 & \mathbf{S}_{\mathrm{brdf}}\end{array}\right)\left(\begin{array}{c}\boldsymbol{a}_{\text {above }} \\ \boldsymbol{a}_{\text {below }} \\ \boldsymbol{a}_{\mathrm{brdf}}\end{array}\right)$, 


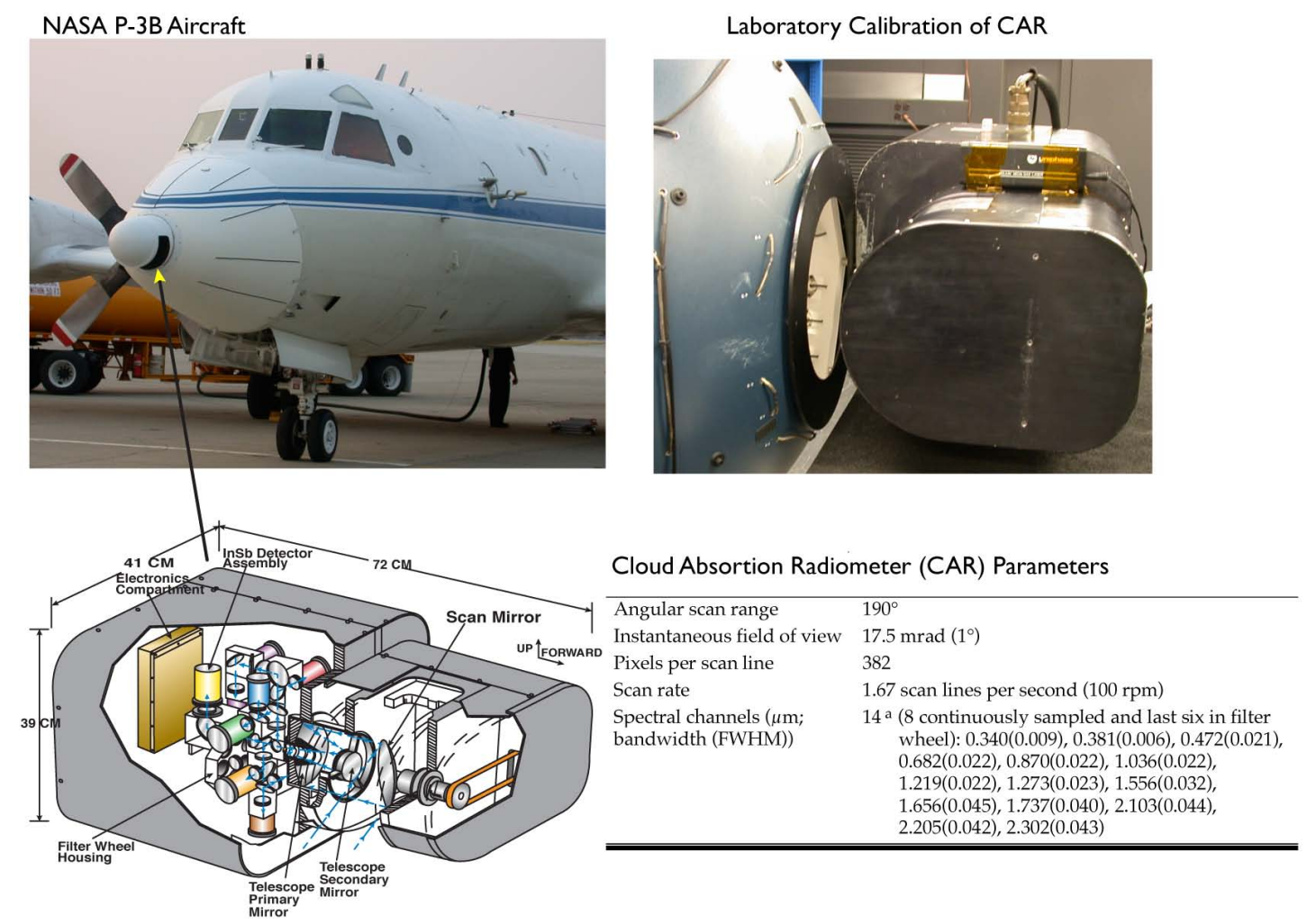

Fig. 2. The CAR was designed to operate from a position mounted on various aircraft. Prior to 2002 the CAR flew aboard the University of Washington's aircraft (Douglas B-23: 1983-1984, C-131A: 1985-1997 and Convair CV-580: 1998-2001). Following retirement of the UW aircraft, the CAR has been integrated on three other Aircraft platforms: South Africa Weather Service, Aerocommander 690A (wing mount, June 2005), Sky Research inc. (USA) Jetstream 31 (nose mount, February 2006-June 2007), and the NASA P-3B (nose mount, 2008). It has 14 narrow spectral bands between 0.34 and $2.30 \mu \mathrm{m}$, six of which $(1.5-2.3 \mu \mathrm{m})$ are defined on the filter wheel and share one detector. Radiometric calibration is performed at the NASA Goddard calibration facility (Gatebe et al. 2007).

where the matrix $\mathbf{S}_{\text {aer }}$ is the same as matrix $\mathbf{S}$ given by Eq. (9). The matrix $\mathbf{S}_{\text {brdf }}$ in Eq. (15) is also a diagonal array matrix given by

$\mathbf{S}_{\mathrm{brdf}} \boldsymbol{a}_{\mathrm{brdf}}=\left(\begin{array}{ccc}\mathbf{S}_{\mathrm{brdf}, 1} & 0 & 0 \\ 0 & \mathbf{S}_{\mathrm{brdf}, 2} & 0 \\ 0 & 0 & \mathbf{S}_{\mathrm{brdf}, 3}\end{array}\right)\left(\begin{array}{c}\boldsymbol{a}_{\mathrm{brdf}, 1} \\ \boldsymbol{a}_{\mathrm{brdf}, 2} \\ \boldsymbol{a}_{\mathrm{brdf}, 3}\end{array}\right)$.

It should be noted that in order to account correctly for the strength of the a priori constraints, each of the different matrices $\mathbf{S}_{v}, \mathbf{S}_{n}, \mathbf{S}_{k}, \mathbf{S}_{\text {brdf,i }}$ in Eqs. (9) and (16) are scaled by the coefficient:

$\left(\gamma_{i}\right)^{1 / 2}=\varepsilon_{\Delta, i} / \varepsilon_{\Delta}$,

$\varepsilon_{\Delta, i}^{2}=\frac{(\Delta x)^{-2 m+1}}{\left(N_{i}-m\right)} \int_{x_{\min }}^{x_{\max }}\left(\frac{d^{m} y_{i}(x)}{d^{m} x}\right)^{2} d x$,

where $y_{i}(x)$ denotes the function $d V(r) / d \ln r, n(\lambda), k(\lambda)$, $\rho_{0}(\lambda), k(\lambda)$ and $\Theta(\lambda)$ for $i=1,2, \ldots, 6$, correspondingly; $\varepsilon_{\Delta}=\varepsilon_{\Delta, 1}$. The values of $\varepsilon_{\Delta, i}^{2}$ in Eq. (17b) were calculated using most unsmooth (variable) examples of correspondent physical functions, i.e., most unsmooth size distributions, spectral dependencies of refractive indices, and BRDF parameters. The detailed description of this concept of setting smoothness constraints is discussed in the papers by Dubovik and King (2000) and Dubovik (2004).

The upper equation in Eq. (8) contains both CAR and AERONET data, and therefore the total "observation vector" $f^{*}$ includes the following component:

$$
\begin{aligned}
& \left(\begin{array}{c}
f_{\text {above }}^{*} \\
f_{\text {AER }}^{*} \\
f_{\text {below }}^{*}
\end{array}\right)=\left(\begin{array}{c}
f_{\text {above }}(a) \\
f_{\text {AER }}(a) \\
f_{\text {below }}(a)
\end{array}\right)+\left(\begin{array}{c}
\Delta f_{\text {above }} \\
\Delta f_{\text {AER }} \\
\Delta f_{\text {below }}
\end{array}\right) \\
& \Rightarrow \quad\left(\begin{array}{c}
f_{1}^{*} \\
f_{2}^{*} \\
f_{3}^{*}
\end{array}\right)=f\left(\begin{array}{c}
a_{1} \\
a_{2} \\
a_{3}
\end{array}\right)+\left(\begin{array}{c}
\Delta f_{1} \\
\Delta f_{2} \\
\Delta f_{3}
\end{array}\right)
\end{aligned}
$$

Accordingly, the weighting matrix $\mathbf{W}$ also has the following simple array structure:

$$
\mathbf{W}=\left(\begin{array}{ccc}
\varepsilon_{1}^{-2} \mathbf{C}_{1} & 0 & 0 \\
0 & \varepsilon_{1}^{-2} \mathbf{C}_{2} & 0 \\
0 & 0 & \varepsilon_{1}^{-2} \mathbf{C}_{3}
\end{array}\right)=\left(\begin{array}{ccc}
\mathbf{W}_{1} & 0 & 0 \\
0 & \mathbf{W}_{2} & 0 \\
0 & 0 & \mathbf{W}_{3}
\end{array}\right),
$$


where $\varepsilon_{1}^{2}$ is the variance of the CAR "above" observations and $\mathbf{C}_{i}$ are the covariance matrices $\mathbf{C}_{i}$ that were assumed diagonal (i.e., all measurements of CAR and AERONET are independent). It should be noted that in principle the variances in matrices $\mathbf{C}_{1}$ (for CAR "above" observations) and $\mathbf{C}_{3}$ (for CAR "below" observations) should be identical (for the same spectral channels, etc.) since they characterize the measurements by the same instrument. However, the accuracy of fitting the CAR "below" observations is expected to be much lower due to inhomogeneity of the surface properties and limitations of the employed three parametric BRDF model to reproduce the actual surface reflectance properties. This means that $\Delta \boldsymbol{f}_{\text {below }}$ can be different from $\Delta f_{\text {above }}$ and includes errors.

The expression of the vector $f^{*}$ is also quite convenient for illustrating information flow in the aerosol retrieval from the CAR/AERONET dataset. For example, the Jacobi matrix $\mathbf{K}_{p}$ from Eq. (10) can written as follows:

$\mathbf{K}=\left(\begin{array}{lll}\mathbf{K}_{11} & \mathbf{K}_{12}^{/ /} & \mathbf{K}_{13}^{/ /} \\ \mathbf{K}_{21} & \mathbf{K}_{22} & \mathbf{K}_{23}^{/ /} \\ \mathbf{K}_{31}^{/ /} & \mathbf{K}_{32}^{/ /} & \mathbf{K}_{33}\end{array}\right)$,

where index " $/ /$ " is used to indicate the matrices with very small elements. Specifically, since uplooking CAR observations $f_{\text {above }}$ are directly affected only by the aerosol layer above the plane and may have only minor sensitivity to surface reflectance properties and aerosol below the plane through effects of multiple scattering, one can outline the following relationships for the $f_{\text {above }}$ derivatives:

$\mathbf{K}_{12}^{/ /} \ll \mathbf{K}_{11}$ and $\mathbf{K}_{13}^{/ /} \ll \mathbf{K}_{11}$.

The AERONET observations $\boldsymbol{f}_{\text {AER }}$ are directly affected by the aerosol in the whole atmospheric column and, only via multiple scattering effects, by surface reflectance properties. In addition, AERONET data have practically no sensitivity to vertical variability of the aerosol. Therefore, the following relationships can be stated for the $f_{\mathrm{AER}}$ derivatives,

$\mathbf{K}_{23}^{/ /} \ll \mathbf{K}_{21} \approx \mathbf{K}_{22}$.

The CAR observations below the plane are dominated by surface reflectance properties. First, the surface reflectance generally is much stronger than scattering of aerosol in the backscattering hemisphere. Second, the layer of the aerosol below the plane is often rather thin. The following relationships for $\boldsymbol{f}_{\text {below }}$ derivatives can be written as

$\mathbf{K}_{31}^{/ /} \ll \mathbf{K}_{33}$ and $\mathbf{K}_{32}^{/ /} \ll \mathbf{K}_{33}$

Thus, taking Eqs. (21) into account, the Jacobi matrix of Eq. (20) can be approximated as follows:

$\mathbf{K} \approx\left(\begin{array}{ccc}\mathbf{K}_{11} & 0 & 0 \\ \mathbf{K}_{21} & \mathbf{K}_{22} & 0 \\ 0 & 0 & \mathbf{K}_{33}\end{array}\right)$.
This structure of matrix $\mathbf{K}_{p}$ explicitly shows that the information about $\boldsymbol{a}_{\text {brdf }}$ mainly comes from $\boldsymbol{f}_{\text {below }}$ CAR observations. The AERONET observations $\boldsymbol{f}_{\mathrm{AER}}$ are critical for deriving $\boldsymbol{a}_{\text {below }}+\boldsymbol{a}_{\text {above }}$; extracting aerosol properties above the plane $\boldsymbol{a}_{\text {above }}$ is only possible due to the availability of $\boldsymbol{f}_{\text {above }}$ CAR observations. Moreover, Eq. (22) suggest the following simple retrieval scheme:

1. $\boldsymbol{a}_{\text {above }}$ is derived from $\boldsymbol{f}_{\text {above }}$ (assuming $\boldsymbol{a}_{\text {below }}$ and $\boldsymbol{a}_{\text {brdf }}$;

2. $\boldsymbol{a}_{\text {below }}+\boldsymbol{a}_{\text {above }}$ is derived from $\boldsymbol{f}_{\mathrm{AER}}$ (assuming $\boldsymbol{a}_{\mathrm{brdf}}$ );

3. $\boldsymbol{a}_{\text {below }}=$ results (ii) - results (i);

4. repeating (i)-(iii) with updated $\boldsymbol{a}_{\text {above }}, \boldsymbol{a}_{\text {below }}$ and $\boldsymbol{a}_{\text {brdf }}$ until the results stop changing.

In principle this iterative scheme should provide rather similar results to the solution using Eqs. (10). However, such solutions produced this way will not be fully optimized in the presence of random noise $\Delta f^{*}$, while the estimates provided by Eqs. (10) is optimum (under the validity of assumptions made) in the sense that it generates the retrieved parameters $\boldsymbol{a}$ with the smallest errors given by Eq. (10c).

A viable sun-sky radiance inversion algorithm requires a model of radiative transfer in order to model the radiative characteristics of the atmosphere by accounting for energy loss and gain using multiple scattering theory. In order to build a better understanding of this problem, we will briefly review the basic equations of radiative transfer, from which an inversion scheme can naturally be designed for the retrieval of the optical characteristics of columnar aerosol (optical depth, single scattering albedo and phase function), or aerosol microstructure, such as particle size and number, as discussed earlier in this section (cf. Dubovik and King, 2000).

\subsection{Radiative transfer modeling}

The fundamental equation of radiative transfer for a plane parallel atmosphere or slab geometry can be expressed in the form of a first order differential equation (cf. Chandrasekhar, 1960):

$\mu \frac{d I(\tau, \mu, \phi)}{d \tau}=I(\tau, \mu, \phi)-S(\tau, \mu, \phi)$,

where $I(\tau, \mu, \phi)$ represents the total radiant intensity (direct and diffuse) at an arbitrary level defined by an optical depth $\tau$ in a unit solid angle along a direction $(\mu, \phi), \mu$ is the cosine of the emergent direction, $\phi$ is the azimuth angle of emergent direction from a reference plane, and $S(\tau, \mu, \phi)$ is the source function, which represents augmentation of radiation in a medium characterized by scattering and emission and represents several processes such as single scattering of the 
direct solar radiation, multiple scattering of the diffuse intensity, and emission by the media. Thus, the source function can be expressed mathematically as

$S(\tau, \mu, \phi)$

$=\frac{\omega_{0}}{4 \pi} \int_{0}^{2 \pi} \int_{-1}^{1} p\left(\mu, \phi ; \mu^{\prime}, \phi^{\prime}\right) I\left(\tau, \mu^{\prime}, \phi^{\prime}\right) d \mu^{\prime} d \phi^{\prime}+S^{\prime}(\tau, \mu, \phi)$,

where $\omega_{0}$ is the single scattering albedo, the ratio of scattering to extinction coefficient, $p()$ is the phase function and describes a scattering event from $\left(\mu^{\prime}, \phi^{\prime}\right)$ to $(\mu, \phi)$. $S^{\prime}$ represents radiation arising from internal or external sources of radiation.

If the total radiance is separated into direct and diffuse radiation fields, Eqs. (23) and (24) can be reduced to the integro-differential equation for the diffuse radiance in the form:

$$
\begin{aligned}
& \mu \frac{d I_{d}(\tau, \mu, \phi)}{d \tau} \\
& =I_{d}(\tau, \mu, \phi)-\frac{\omega_{0}}{4 \pi} \int_{0}^{2 \pi} \int_{-1}^{1} p\left(\mu, \phi ; \mu^{\prime}, \phi^{\prime}\right) I_{d}\left(\tau, \mu^{\prime}, \phi^{\prime}\right) d \mu^{\prime} d \phi^{\prime} \\
& -\frac{\omega_{0}}{4} F_{0} p\left(\mu, \phi ;-\mu_{0}, \phi_{0}\right) \exp \left(-\tau / \mu_{0}\right)+S^{\prime}(\tau, \mu, \phi)
\end{aligned}
$$

Using an upper and lower boundary conditions defined by:

$$
I^{-}(\tau, \mu, \phi)=\delta\left(\mu-\mu_{0}\right) \delta\left(\phi-\phi_{0}\right) \pi F_{0},
$$

$I^{+}(\tau, \mu, \phi)$

$=\frac{1}{\pi} \int_{0}^{2 \pi} \int_{0}^{1} R\left(\mu, \phi ; \mu^{\prime}, \phi^{\prime}\right) I^{-}\left(\tau,-\mu^{\prime}, \phi^{\prime}\right) d \mu^{\prime} d \phi^{\prime}$,

where the delta function $\delta()$ is zero everywhere except at the origin and $R\left(\mu, \phi ; \mu^{\prime}, \phi^{\prime}\right)$ is the bidirectional reflectance distribution function, which depends on the incidence $\left(\mu^{\prime}, \phi^{\prime}\right)$ and reflectance $(\mu, \phi)$ directions.

Note that, if the surface is black (e.g., over the ocean at near-infrared wavelengths outside of sunglint), $R(\mu, \phi$; $\left.\mu^{\prime}, \phi^{\prime}\right)=0$. For $R\left(\mu, \phi ; \mu^{\prime}, \phi^{\prime}\right)=$ constant, the surface reflectance is described by Lambert's law and for a surface dominated by specular reflection, e.g., a quiet flat ocean, $R\left(\mu, \phi ; \mu^{\prime}, \phi^{\prime}\right)=\delta\left(\mu-\mu^{\prime}\right) \delta\left(\phi-\phi^{\prime}\right) R_{f}$, where $R_{f}$ is given by the Fresnel's law. In reality $R$ is generally a complex function of both incidence and reflectance directions and is not well known for various kinds of surface boundaries and sometimes is estimated by empirical equations.

The simplest methods for finding a solution include Trapezium and Simpson rules, while the more advanced techniques such as Gaussian quadrature rule are suitable for integration of complex functions and considered better for numerical integration. Other solution methods and techniques are described in Chandrasekhar's book (Chandrasekhar, 1950). The discrete-ordinate method (DISORT), spherical-harmonic method, adding-doubling method, and Monte Carlo are now the main computation methods used and are reviewed in a book by Lenoble (1985).

Our retrieval algorithm is based on the discrete-ordinate method (cf. Thomas and Stamnes, 1999), implemented numerically through a code written in FORTRAN by Nakajima and Tanaka (1988). The method applies to vertically inhomogeneous, non-isothermal, plane-parallel media and includes all the physical processes such as thermal emission, scattering, absorption, bidirectional reflection, and thermal emission at the boundary. The method supposes that radiation can be characterized by a discrete number of directed streams (discrete ordinates) to mimic the true variation of intensity with angle. The problem is simplified by considering only two rays in the opposite directions $u= \pm 1$, which give reasonably accurate results. DISORT contains many expressions that allow us to implement simple solutions and offers substantial computational advantages when only integrated quantities such a flux reflectance and transmittance are required.

Surface reflectance in the code is implemented either through the Lambertian (isotropic) approximation or semi-empirical bidirectional reflectance distribution function (BRDF) models such as Coupled Surface-Atmosphere Reflectance (CSAR) model (Rahman et al., 1993a, b) or RossLi BRDF model (Lucht et al., 2000; Wanner et al., 1995, 1997). For an ocean surface, we use the Cox and Munk model (Cox and Munk, 1954a, b; Nakajima and Tanaka, 1983).

Given a method of solution of the radiative transfer equation for different conditions in a plane-parallel media, we can now look at the measurements used to test the new algorithm.

\section{Measurements}

In this section, we will describe the CAR and AERONET measurements to provide insights into the data used in the aerosol and surface bidirectional reflectance retrieval.

\subsection{CAR measurements}

The CAR data were selected from four different campaigns: (a) Southern African Regional Science Initiative 2000 (SAFARI 2000) over Mongu, Zambia $\left(15.44^{\circ} \mathrm{S}\right.$, $23.23^{\circ} \mathrm{E} ; \theta_{0}=32.16^{\circ} \pm 0.52^{\circ}$ ) on 6 September 2000, (b) Intercontinental Chemical Transport Experiment-Phase B (INTEX-B) over Mexico City, Mexico $\left(19.45^{\circ} \mathrm{N}, 99.16^{\circ} \mathrm{W}\right.$; $\theta_{0}=32.55^{\circ} \pm 0.42^{\circ}$ ) on 6 March 2006, (c) Cloud and Land Surface Interaction Campaign (CLASIC) over the ARM Central Facility, Lamont, Oklahoma, USA $\left(36.61^{\circ} \mathrm{N}\right.$, 


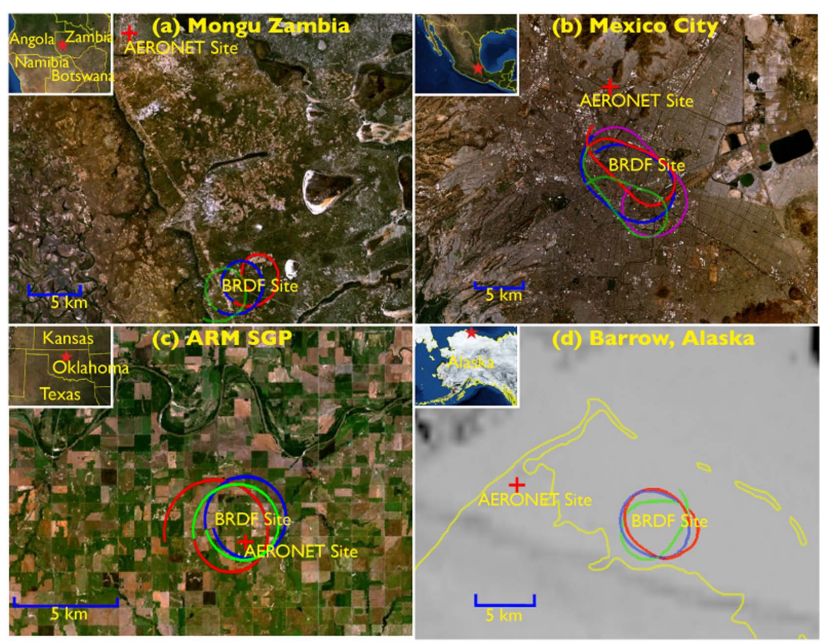

Fig. 3. Location of CAR BRDF Measurements: (a) Mongu, Zambia $\left(15.44^{\circ} \mathrm{S}, 23.23^{\circ} \mathrm{E}\right.$, (b) Mexico City $\left(19.45^{\circ} \mathrm{N}, 99.16^{\circ} \mathrm{W}\right),(\mathbf{c})$ SGP Central Facility, Oklahoma, USA $\left(36.61^{\circ} \mathrm{N}, 97.50^{\circ} \mathrm{W}\right)$, and (d) Elson Lagoon, Barrow, Alaska, USA $\left(71.32^{\circ} \mathrm{N}, 156.27^{\circ} \mathrm{W}\right)$. Actual circular flight tracks during BRDF measurements are shown in color superimposed on high-resolution satellite imagery from World Wind (worldwind.arc.nasa.gov). We used the $250 \mathrm{~m}$ resolution MODIS-Aqua image taken on 6 April 2008 for Barrow. The AERONET sunphotometer sites used in the retrieval are also shown marked by "+" symbol.

$97.50^{\circ} \mathrm{W} ; \theta_{0}=66.81^{\circ} \pm 0.73^{\circ}$ ) on 28 June 2007 , and (d) the Arctic Research of the Composition of the Troposphere from Aircraft and Satellites (ARCTAS) over Elson Lagoon, Barrow, Alaska, USA $\left(71.32^{\circ} \mathrm{N}, 156.27^{\circ} \mathrm{W} ; \theta_{0}=68.71^{\circ} \pm 0.15^{\circ}\right)$ on 6 April 2008. Figure 3 shows the locations of these experiments, plotted on high resolution satellite images (from the NASA World Wind, worldwind.arc.nasa.gov, which leverages Landsat satellite imagery and Shuttle Radar Topography Mission data). In each panel of Fig. 3, we also show the flight tracks superimposed over the sites where CAR measurements were taken, plus locations of nearby AERONET sites. Note that for Barrow, we used an image from the Moderate Resolution Imaging Spectroradiometer (MODIS) at $250 \mathrm{~m}$ resolution for 6 April to show the actual surface conditions observed during the measurements. The flight tracks are nearly circular, especially over Barrow, which were performed by the NASA P-3B aircraft as opposed to those performed by the University of Washington aircraft, Convair CV-580 over Mongu and Sky Research Jetstream-31 over Mexico City and Oklahoma. The sites show different surface characteristics, and are influenced by different aerosol source regions, hence, provide diverse conditions for testing the new inversion algorithm over land.

The Mongu site is located in western Zambia, adjacent to the massive Zambezi River flood plain in an area dominated by Miombo woodland (tree height $\sim 16-18 \mathrm{~m}$ ), grassland, seasonal marsh, and crops (compare with Plate $4 \mathrm{c}$ in Gatebe et al. 2003). The aerosol loading is dominated by biomass burning aerosols in September (cf. Eck et al., 2003). Mexico City is located in the central part of the Trans-Mexican plateau and has an approximate area of $\sim 9000 \mathrm{~km}^{2}$ with the basin sitting at an altitude of $\sim 2200 \mathrm{~m}$ above mean seal level (AMSL), which is the highest valley in the region, and surrounded by mountains that reach elevations of over $5000 \mathrm{~m}$ a.m.s.l. Mexico City is the largest city in North America and the 3rd largest city in the world, with a population of over 20 million people. Mexico City is dominated by urbanscape (concrete, asphalt road, etc.) and aerosol loading is associated with urban-industrial aerosol. The ARM Central Facility site located in Lamont, Oklahoma is on a relatively homogenous landscape with widespread wheat fields and scattered corns fields, pastures and bare soil fields. Aerosol loading is dominated by smoke from agricultural burning, local fire sources, oil refineries and dust plumes from the surrounding agricultural fields. Elson Lagoon near Barrow, Alaska, is snow covered in April and the aerosol loading is characterized by brown haze attributed to transboundary anthropogenic pollution, thought to originate from coal-burning in northern latitudes, especially from Asia. Each location has a nearby AERONET sunphotometer site as shown in Fig. 3.

The CAR instrument (Fig. 2; Gatebe et al., 2003; King et al., 1986) provides a rich dataset consisting of multiangular and multispectral radiance measurements at fourteen spectral bands between 0.34 and $2.30 \mu \mathrm{m}$, and has operated on different airborne platforms: University of Washington aircraft (B-23, C-131A and CV-580), Sky Research Inc. Jetstream31 aircraft, South Africa Weather Service Aerocommander 690A, and the NASA P-3B aircraft (for more details see car.gsfc.nasa.gov). In the normal mode of operation, data are sampled simultaneously and continuously on nine individual detectors. Eight of the data channels are for spectral bands from $0.34-1.27 \mu \mathrm{m}$, which are always registered during the operation, while the ninth data channel is spatially coregistered and selected from among six spectral channels $(1.55-2.30 \mu \mathrm{m})$ on a filter wheel. The filter wheel can either cycle through all six spectral bands at a prescribed interval (usually changing filter every fifth scan line), or lock onto any one of the six spectral bands, mostly $1.656,2.103$ or $2.205 \mu \mathrm{m}$, and sample it continuously. The CAR scan mirror rotates $360^{\circ}$ in a plane perpendicular to the direction of flight and the data are collected through a $190^{\circ}$ aperture that allows observations of the earth-atmosphere scene around the starboard horizon from local zenith to nadir.

The measurements described in this study were taken in a circular flight pattern, about $3 \mathrm{~km}$ in diameter, above the surface ( $\sim 600$ m a.g.l.; Gatebe et al., 2003). This pattern is used to acquire measurements of bidirectional reflectance distribution function (BRDF) of the surface-atmosphere system under clear sky conditions in all directions. At an aircraft bank angle of $20-30^{\circ}$, the plane takes roughly $2-3 \mathrm{~min}$ to complete an orbit. Because of flight restrictions over Mexico City, however, it was difficult to maintain a constant bank 
angle, instead the flight pattern prescribed a racetrack and took about 4-5 min (cf. Fig. 3b). Multiple circular orbits are acquired over the surface so that average BRDFs smooth out small-scale surface and atmospheric inhomogeneities. The instrument is set to point in any given direction and any angle between $0^{\circ}$ and $360^{\circ}$ by a servo-control system. This system helps to compensate for variations in airplane roll angle down to a fraction of a degree. However, it is still necessary to make geometric correction during post-processing to allow pixels to be matched to their actual scan angle by use of airplane roll, pitch, and the horizon pixel, which corresponds to a scan angle of $90^{\circ}$, and is easily identified on a scan line by the contrast between sky and surface, especially on a clear day. Geometrically corrected quicklook images can be found on the car website: car.gsfc.nasa.gov/data. A plot of sky radiance as a function of azimuthal angle helps in identifying asymmetry due to errors in the geometrical correction.

Among the unique features of the CAR is the fact that the instrument observes the reflected solar radiation at a fine angular resolution defined by an instantaneous field of view of $1^{\circ}$. It is normally set to scan from nadir all the way to the zenith, but can also be set to observe the entire downwelling scattered radiation field at approximately half-degree intervals through $190^{\circ}$ aperture at a rate of 100 scans per minute. Therefore, the CAR collects between 76400 and 114600 directional measurements of radiance per channel per complete orbit, which amounts to between 687600 and 1031400 measurements per orbit for nine channels. Data used for the inversion are selected from a wide range of angular scattering angles and wavelengths using the following strategy:

1. Average BRDF measurements over all the circular orbits for both sky radiance and surface reflected radiance.

2. Check symmetry of the sky and surface radiances about the solar principal plane. If the absolute difference between the left- and right-side exceeds a given threshold, usually a number between 1 and $10 \%$, the pair is rejected and not included in the inversion dataset. If the difference between the pairs is less than or equal to the threshold, an average of the two values is computed. Note that a smaller threshold eliminates many data pairs, while a larger threshold allows inclusion of more data points. The total number of data points is set to 5000 , which is arbitrarily set to speed up the retrieval.

3. Remove measurements whose scattering angles are $\leq 10^{\circ}$. This is done to ensure that saturated pixels that are especially close to the solar direction are excluded from the inversion.

4. For a given altitude and average solar zenith angle, data are stored in a special input format for the inversion, where each measurement $I_{\mathrm{CAR}}(\lambda, \theta, \phi)$ is indexed to the corresponding wavelength and observational angles.
The data are now ready for inversion or can be combined with other datasets such as the AERONET sunphotometer measurements, discussed in the following subsection.

\subsection{Sunphotometer measurements}

The sunphotometer automatically tracks the sun and obtains spectral solar flux density and sky radiance. Two different observation sequences are used for acquiring sky radiances in the AERONET program. These are the almucantar and principal plane scan sequences (cf. Holben et al., 1998). The almucantar scan sequence involves a series of observations from a single channel made in a sweep across the solar disk at a constant elevation angle through $360^{\circ}$ of azimuth, which is repeated for four channels to complete an almucantar sequence. Each $360^{\circ}$ cycle takes about $40 \mathrm{~s}$. Four or more almucantar sequences are made with the standard AERONET instruments each day at an optical airmass of 4 , 3,2 , and 1.7 during both morning and afternoon, and hourly between 9 a.m. and 3 p.m. local solar time, skipping only the noon almucantar for the polarization instruments. Note that a direct sun observation is made during each spectral almucantar sequence. The principal plane scan sequence involves the instrument sweeping through the sun in the principal plane making observations from a single channel, which takes about $30 \mathrm{~s}$, then repeated for several channels to complete the sequence. Principal plane observations are made hourly when the optical airmass is less than 2. Optical thickness combined with almucantar or principal plane sky radiances at four standard AERONET spectral bands (0.44, 0.67, 0.87 , and $1.02 \mu \mathrm{m}$ ) are considered as the basic set of groundbased observations for the inversion. However, for high sun elevations, principal plane observations are used instead of almucantar due to the limited range of scattering angles for the almucantar measurements, which reduces the aerosol retrieval accuracy (Dubovik et al., 2000). The accuracy of the AERONET aerosol optical thickness measurements is $\sim 0.01$ for $\lambda \geq 0.44 \mu \mathrm{m}$, and the uncertainty in measured sky radiances due to calibration errors is $\sim 5 \%$ (cf. Holben et al., 1998).

In this study, we used AERONET spectral aerosol optical thickness and almucantar or principal plane sky radiance measurements at four narrow wavelength bands centered at $0.44,0.67,0.87$, and $1.02 \mu \mathrm{m}$. We downloaded AERONET direct and almucantar and/or principal plane sky radiances coinciding with CAR measurements for Mongu $\left(15.25^{\circ} \mathrm{N}\right.$, $23.15^{\circ} \mathrm{W}$, alt. $1107 \mathrm{~m}$, a.m.s.l.) for 6 September 2000 $\left(08: 34\right.$ UTC; $\left.\theta_{0}=34.51^{\circ} ; \tau_{a}(0.5 \mu \mathrm{m})=1.352\right)$, Mexico City at $\mathrm{T}_{0}\left(19.49^{\circ} \mathrm{N}, 99.15^{\circ} \mathrm{W}\right.$, alt. $2257 \mathrm{~m}$ a.m.s.l. $)$ for $6 \mathrm{March}$ $2006\left(17: 57\right.$ UTC; $\left.\theta_{0}=27.94^{\circ} ; \tau_{a}(0.5 \mu \mathrm{m})=0.347\right)$, SGP Central Facility $\left(36.61^{\circ} \mathrm{N}, 97.49^{\circ} \mathrm{W}\right.$, alt. $318 \mathrm{~m}$ a.m.s.l.) for 24 June $2007\left(13: 13 \mathrm{UTC} ; \theta_{0}=68.39^{\circ} ; \tau_{a}(0.5 \mu \mathrm{m})=0.150\right)$ and Barrow $\left(71.31^{\circ} \mathrm{N}, 156.66^{\circ} \mathrm{W}\right.$, alt. $0 \mathrm{~m}$ a.m.s.l.) for 7 April 2008 (00:38 UTC; $\theta_{0}=67.46^{\circ} ; \tau_{a}(0.5 \mu \mathrm{m})=0.125$ ). 

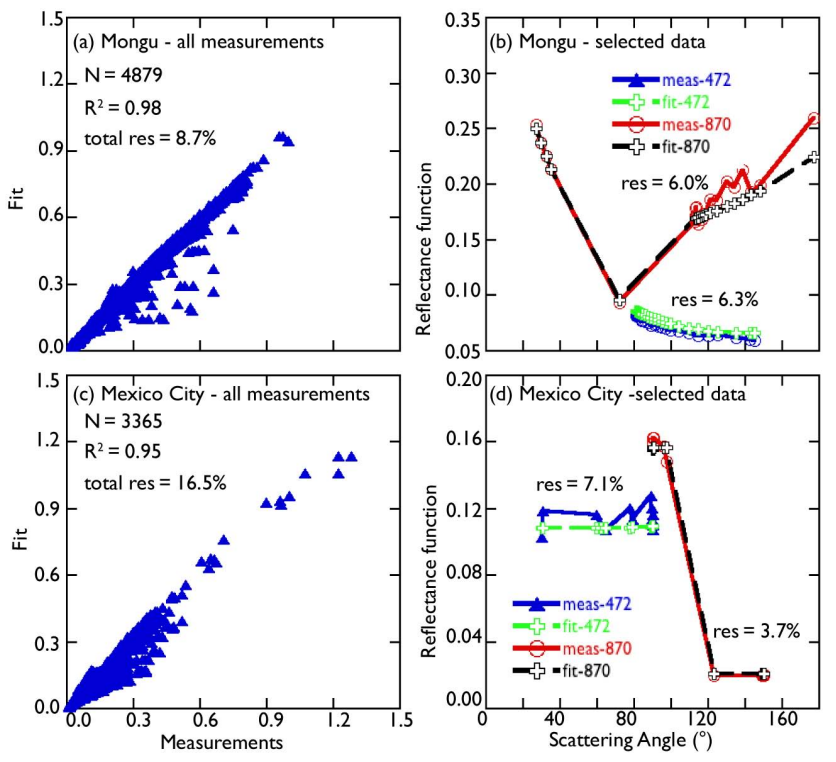

Fig. 4. Scatter plots showing the relationship between predicted and observed CAR and AERONET values that were used in the retrieval of aerosol and surface BRF for Mongu and Mexico City. The total number of data points $(\mathrm{N})$, coefficient of variation assuming a linear fit, and total optical residual as defined in Eq. (27), are indicated in each case. Plots (b) and (d) show comparison between predicted and observed reflectances at 0.472 and $0.870 \mu \mathrm{m}$ as a function of scattering angle. The optical residual error for Mongu at $0.472 \mu \mathrm{m}$ $(0.870 \mu \mathrm{m})$ is $6.0 \%(6.3 \%)$, while for Mexico City the residual error at $0.472 \mu \mathrm{m}(0.870 \mu \mathrm{m})$ is $7.1 \%(3.7 \%)$.

These data were then combined with the CAR data for a joint retrieval using the new algorithm.

\section{Results}

The purpose of this section is to demonstrate the new inversion algorithm with results of inversion of data from four different field campaigns. These cases comprise a variety of surface types suitable for testing the robustness of the new algorithm. We will show results of the aerosol size distribution, complex index of refraction, and single scattering albedo for two layers, both above and below the aircraft altitude, and surface bidirectional reflectance factor (BRF) parameters. In order to fully understand the strengths and limitations of the current algorithm, we plan to do a sensitivity analysis in a separate study; however, the work of Dubovik and King (2000) and Dubovik et al. (2000), which uses a similar approach for aerosol inversion, provides a good foundation for understanding the new approach.

\subsection{Fitting the measurements}

As mentioned in Sect. 2, our retrieval approach uses a theoretical model to simultaneously search for the best fit of all input data from the CAR and/or AERONET taking into ac-
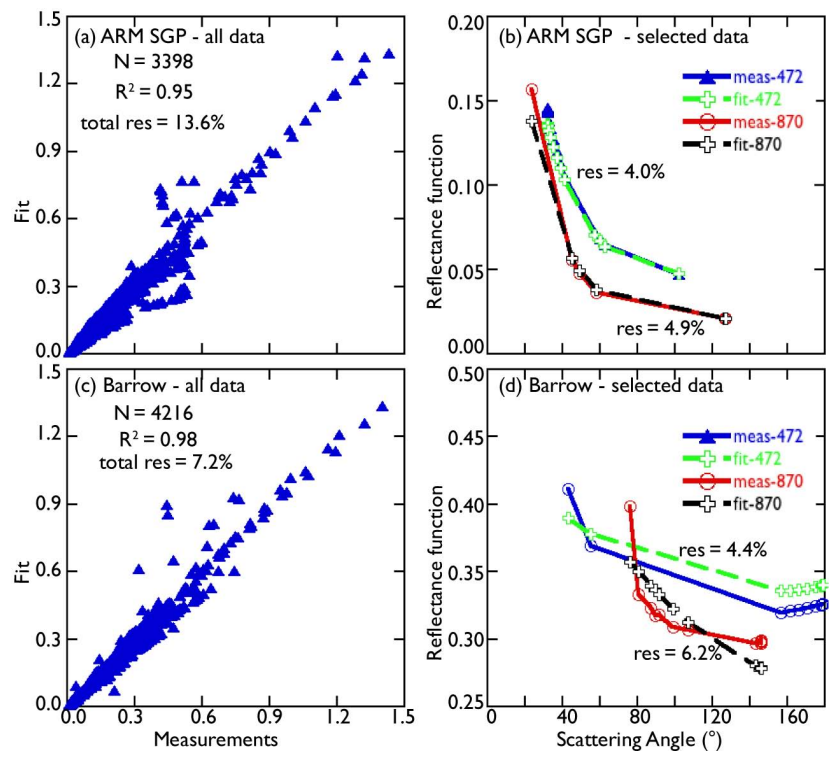

Fig. 5. Scatter plots showing the relationship between predicted and observed CAR and AERONET values that were used in the retrieval of aerosol and surface BRF for Oklahoma and Barrow. The total number of data points $(\mathrm{N})$, coefficient of variation assuming a linear fit, and total optical residual as defined in Eq. (27), are indicated in each case. Plots (b) and (d) show comparison between predicted and observed reflectances at 0.472 and $0.870 \mu \mathrm{m}$ as a function of scattering angle. The optical residual error for Oklahoma at $0.472 \mu \mathrm{m}(0.870 \mu \mathrm{m})$ is $4.0 \%(4.9 \%)$, while for Elson Lagoon the residual error at $0.472 \mu \mathrm{m}(0.870 \mu \mathrm{m})$ is $4.4 \%(6.2 \%)$.

count different levels of accuracy of the two datasets. The quality of the fit is the most important criterion for identifying a successful retrieval and is indicated by the value of the smallest residual, which is sensitive to the presence of errors in the experimental observations. Unlike AERONET retrievals that are considered successful only if residual values are no greater than 3-5\%, the residual values in the combined retrieval are much larger, but averages no larger than 15\%. The scatter plots in Figs. 4 and 5 show the nature of the relationship between predicted and observed CAR and AERONET data used in the retrieval of aerosol and surface BRF for Mongu, Mexico City, Oklahoma, and Barrow. The total number of data points $(N)$ used in each case is shown in the figure. The coefficient of determination $\left(R^{2}\right)$ shown in the scatter plots are here used to indicate the percent of data that would be closest to a line of best fit. Note that, in principle, the solution corresponds to the minimum of the function given by Eq. (11). However, in order to provide the parameter practical meaning more suitable for user interpretation, we have analyzed the accuracy of fitting only the optical measurements. Correspondingly, the best fit between measured $\left(f_{i}^{*}\right)$ and calculated $\left(f_{i}\right)$ radiances was considered the one having the minimum root-mean-square-error in the 
Table 1. CAR optical residual errors (\%) for Mongu.

\begin{tabular}{|c|c|c|c|c|c|c|c|c|}
\hline \multirow[t]{2}{*}{ Scan Angle $\left({ }^{\circ}\right)$} & \multicolumn{8}{|c|}{ Wavelength $(\mu \mathrm{m})$} \\
\hline & 0.340 & 0.381 & 0.472 & 0.682 & 0.870 & 1.036 & 1.219 & 1.273 \\
\hline 0 & 6.8 & 3.2 & 2.2 & 1.4 & 4.1 & 5.6 & 4.7 & 3.2 \\
\hline 5 & 8.2 & 1.8 & 3.8 & 0.6 & 1.9 & 2.4 & 11.2 & 8.0 \\
\hline 10 & 6.4 & 2.4 & 2.6 & 5.2 & 14.8 & 13.7 & 18.2 & 27.7 \\
\hline 15 & 5.4 & 3.2 & 3.1 & 8.6 & 26.4 & 27.4 & 33.2 & 43.5 \\
\hline 20 & 5.1 & 4.3 & 4.6 & 13.9 & 39.0 & 49.7 & 64.9 & 75.1 \\
\hline 25 & 6.2 & 4.0 & 2.8 & 1.8 & 2.4 & 1.1 & 6.9 & 17.5 \\
\hline 32 & 3.8 & 3.3 & 1.1 & 0.9 & 1.3 & 1.2 & 8.3 & 16.0 \\
\hline 35 & 5.6 & 2.3 & 2.1 & 1.6 & 2.2 & 2.4 & 10.8 & 18.2 \\
\hline 40 & 6.0 & 2.6 & 1.8 & 1.2 & 1.5 & 4.2 & 10.4 & 11.0 \\
\hline 45 & 4.6 & 3.2 & 2.3 & 10.5 & 28.8 & 63.5 & 73.8 & 64.5 \\
\hline 50 & 4.7 & 3.6 & 2.3 & 5.8 & 14.7 & 30.7 & 35.8 & 31.2 \\
\hline 55 & 4.9 & 3.4 & 1.3 & 3.8 & 10.6 & 19.4 & 20.6 & 17.1 \\
\hline 60 & 5.8 & 2.3 & 1.2 & 2.7 & 7.4 & 14.8 & 15.8 & 10.4 \\
\hline 64 & 6.4 & 2.9 & 1.2 & 2.3 & 6.5 & 13.4 & 14.6 & 9.4 \\
\hline 66 & 6.2 & 2.9 & 1.5 & 2.1 & 6.5 & 12.4 & 13.1 & 9.0 \\
\hline 68 & 6.7 & 2.9 & 1.5 & 1.9 & 5.6 & 12.1 & 14.1 & 8.5 \\
\hline 70 & 7.6 & 2.9 & 1.7 & 1.8 & 5.5 & 9.7 & 14.5 & 7.9 \\
\hline 80 & 10.7 & 3.7 & 2.8 & 1.0 & 5.1 & 4.5 & 14.3 & 5.0 \\
\hline 85 & 15.5 & 7.0 & 6.3 & 3.4 & 3.5 & 10.1 & 22.9 & 8.0 \\
\hline 100 & 13.7 & 6.0 & 4.8 & 4.3 & 2.7 & 4.6 & 6.0 & 4.7 \\
\hline 113 & 12.5 & 8.2 & 6.3 & 5.2 & 4.0 & 3.3 & 3.1 & 2.5 \\
\hline 115 & 12.1 & 12.0 & 6.0 & 7.4 & 4.1 & 3.2 & 3.9 & 3.5 \\
\hline 117 & 11.5 & 12.0 & 5.4 & 6.3 & 3.2 & 3.1 & 3.8 & 3.3 \\
\hline 120 & 9.4 & 11.6 & 4.8 & 6.9 & 3.8 & 3.9 & 4.3 & 4.0 \\
\hline 125 & 8.7 & 12.4 & 4.3 & 5.8 & 3.2 & 4.0 & 4.3 & 4.0 \\
\hline 130 & 6.5 & 15.7 & 4.1 & 6.0 & 2.7 & 3.3 & 3.7 & 3.3 \\
\hline 135 & 6.4 & 13.1 & 4.1 & 5.6 & 4.7 & 4.9 & 5.7 & 5.1 \\
\hline 140 & 8.3 & 15.8 & 5.9 & 8.8 & 6.1 & 6.1 & 6.6 & 6.2 \\
\hline 145 & 7.2 & 14.2 & 4.3 & 7.6 & 6.0 & 5.7 & 5.9 & 5.4 \\
\hline 150 & 6.7 & 15.5 & 8.8 & 10.4 & 6.9 & 6.1 & 5.7 & 5.3 \\
\hline 155 & 7.3 & 14.3 & 9.4 & 11.0 & 7.1 & 7.1 & 7.5 & 7.2 \\
\hline 160 & 7.8 & 14.2 & 10.2 & 11.0 & 7.0 & 6.1 & 5.6 & 5.7 \\
\hline 165 & 6.9 & 16.7 & 8.1 & 10.7 & 4.9 & 4.1 & 4.7 & 4.9 \\
\hline 170 & 7.6 & 24.3 & 6.8 & 7.0 & 4.1 & 3.3 & 3.3 & 3.4 \\
\hline 175 & 7.0 & 19.7 & 8.8 & 7.1 & 6.8 & 7.5 & 7.8 & 6.7 \\
\hline 180 & 8.0 & 15.0 & 12.6 & 10.3 & 12.6 & 13.4 & 14.2 & 12.6 \\
\hline
\end{tabular}

Average residual: $8.7 \%$

logarithmic space (RMSELS) defined as:

RMSELS $=\left(\sqrt{\left.\frac{1}{N} \sum_{i=1}^{N}\left[\ln \left(f_{i}^{*}\right)-\ln \left(f_{i}\right)\right]^{2}\right)} \cdot 100\right.$,

where RMSELS is the value of the residual in $\%, N$ is the number of measurements, $f_{i}^{*}$ are the measurements and $f_{i}$ represents the fit. The total optical residual as defined in Eq. (27) is indicated on the scatter plots and a comparison between predicted and observed reflectances at 0.472 and $0.870 \mu \mathrm{m}$ as a function of scattering angle are also shown, in addition to the corresponding residual values. Note that for this view geometry, only measurements in the upward hemisphere (scattering angles less than $90^{\circ}$ ) at $0.87 \mu \mathrm{m}$ were used in retrieval for Mongu, but not any measurements at $0.472 \mu \mathrm{m}$. For Mexico City, in contrast, there are no values of $0.47 \mu \mathrm{m}$ in the upwelling (scattering angle greater than $90^{\circ}$ range) that met the criteria, and no $0.87 \mu \mathrm{m}$ values in the downwelling direction (scattering angle less than $90^{\circ}$ ). Table 1 shows the residual values for Mongu at different CAR wavelengths and scan angles. Similar tables are available for the other cases, but will not be presented here.

The wide spectral and angular range afforded by the CAR helps to mitigate random error retrievals especially in the re- trieved complex index of refraction, which is sensitive to a limited angular range (cf. Dubovik et al. 2000). The size distribution retrievals are not as sensitive to the angular range either in the presence or absence of optical thickness.

\subsection{Retrieved aerosol properties}

In this section various aerosol physical parameters (size distribution, single scattering albedo, and complex index of refraction) are retrieved from the combined data. These parameters were retrieved successively from the combined datasets. However, we would like to observe that there is no better way to validate these results. This is the same predicament facing AERONET retrievals that have become the standard for validating satellite aerosol optical thickness retrievals. We do not yet have a suitable technique for validating column retrievals of aerosol size distribution, complex index of refraction, and single scattering albedo. It should be noted that the retrieval of refractive index and single scattering albedo is very difficult even from AERONET data alone, where retrieval is restricted to certain conditions (e.g., $\tau_{a}(440)>0.5$ ). In our analysis, we show all the parameters in all conditions, but we are going to study the errors in detail in a follow up work.

\subsubsection{Aerosol size distribution}

Figure 6 shows the volume size distribution retrieved from combined CAR and AERONET measurements over (a) Mongu, Zambia on 6 September 2000, (b) Mexico City, Mexico on 6 March 2006, (c) Southern Great Plains Central Facility, Oklahoma, USA on 24 June 2007, and (d) Elson Lagoon near Barrow, Alaska, USA on 6 April 2008. The volume size distribution is retrieved in two layers, one above the aircraft (blue curve) and the other below the aircraft (green curve). The red curve represents the total column, which is the sum of the two layers, and should be comparable to the AERONET retrievals.

The shape of the volume size distribution at Mongu for both layers is a bimodal lognormal size distribution with a strong peak at $r=0.15 \mu \mathrm{m}$ and a secondary peak at $r=6.64 \mu \mathrm{m}$. The total aerosol optical thickness is dominated by submicron mode aerosol particles from biomass burning activities in southern Africa that is common at this time of the year as shown in Dubovik et al. (2002) and Eck et al. (2003). The aerosol mostly appears above the aircraft (altitude of $\sim 600 \mathrm{~m}$ above ground), which agrees with the findings of Pilewskie et al. (2003). The extrapolated aerosol optical thickness at $0.500 \mu \mathrm{m}$ above the aircraft is 1.01 , compared to 1.35 measured from the ground by AERONET.

The shape of the volume size distribution for the layer above the aircraft over Mexico City is trimodal with modal peaks at $r=0.15,1.30$, and $3.86 \mu \mathrm{m}$. The shape is bimodal in the layer below the aircraft with modal peaks at $r=0.19$ and $3.86 \mu \mathrm{m}$. Although submicron particles appear to dominate 


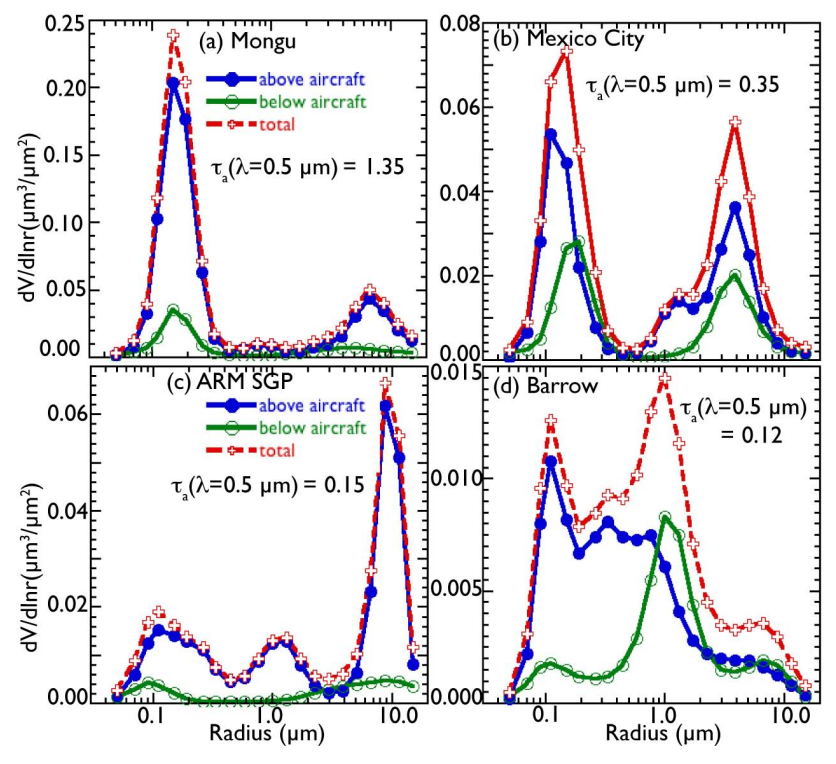

Fig. 6. Aerosol volume size distribution for spherical particles retrieved from combined CAR and AERONET measurements over (a) Mongu, Zambia, 6 September 2000, (b) Mexico City, Mexico, 6 March 2006, (c) Southern Great Plains, Central Facility, Oklahoma, USA, 24 June 2007, and (d) Barrow, Alaska, USA, 6 April 2008. The volume size distribution is separated into two layers above and below the aircraft.

in both layers, there is a significant contribution to the total optical thickness from particles with $r>1 \mu \mathrm{m}$.

The shape of the volume size distribution over the SGP site in Oklahoma is trimodal in the layer above the aircraft with peaks at $r=0.10,1.30$, and $8.71 \mu \mathrm{m}$. The shape is unimodal for the layer below aircraft with a peak at $r=0.09 \mu \mathrm{m}$. The optical thickness is clearly dominated by coarse particles. The size distribution obtained for the above aircraft aerosol is very different from distributions usually observed for the atmospheric aerosol. In difference with typical predominantly bi-modal size distributions observed by AERONET (e.g. see climatology by Dubovik et al., 2002), the retrieved distribution for aerosol above aircraft has the trimodal distribution with rather narrow shape of each mode. The retrievals of such type are occasionally observed in analysis of AERONET data in presence of homogenous thin cirrus over ground-based sun-photometers. Since cirrus clouds have particles of much larger sizes than 15 microns in radius (that is maximum size assumed in the retrieval algorithm) and due to the fact that AERONET observations do not have sufficient sensitivity to such larger particle sizes, the aerosol observation corresponding to tri-modal size distributions are usually flagged as "cloud-contaminated" and eliminated from Level 2.0 "cloud-free" AERONET database. In our case, the appearance of cirrus cloud may have a strong effect mainly on the observations above the aircraft. Indeed, the retrieval of aerosol under the aircraft shows the usual bi-modal size dis-

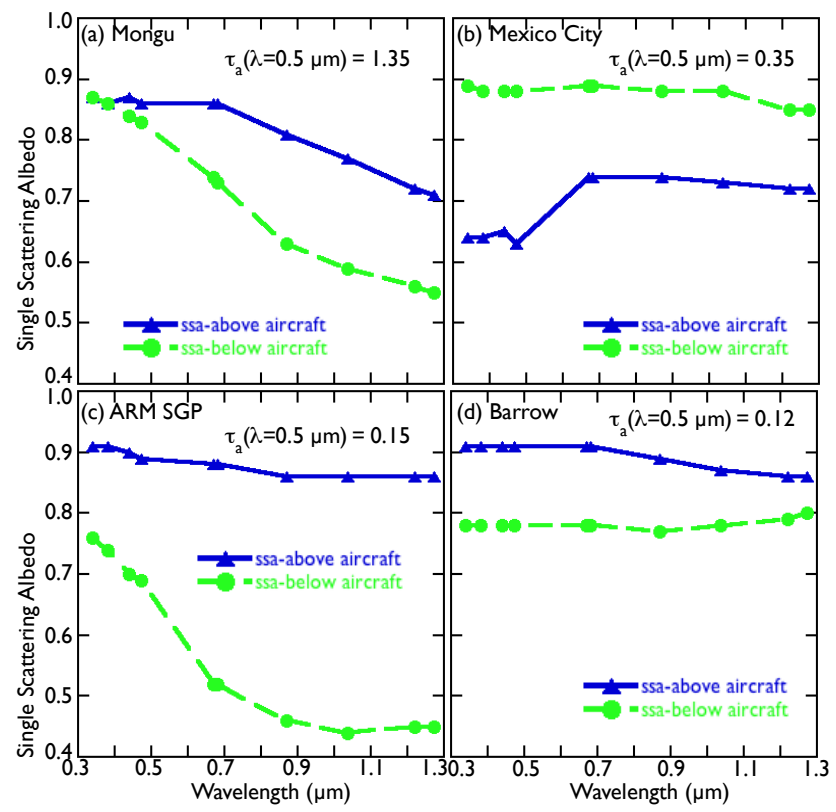

Fig. 7. Single Scattering Albedo (SSA) retrieved from combined CAR and AERONET measurements over Mongu, Zambia on 6 September 2000, Mexico City, Mexico, 6 March 2006, SGP Central Facility, Oklahoma, 24 June 2007 and Elson Lagoon, Barrow, Alaska, 6 April 2008. The single scattering albedo is separated into two layers above and below the aircraft. Note that the magnitude of uncertainty in SSA is larger for low $\tau_{a}$ (see Sect. 4.2.2).

tribution with notable presence of fine particles. Therefore, we anticipate that the retrieved parameters of underlying surface reflectance and properties of aerosol under the aircraft were not significantly affected by the presence of cirrus.

For Barrow, the aerosol optical thickness is dominated by submicron particles, with very little contribution from micron size particles. The shape of the volume size distribution is trimodal in the layer above the aircraft with peaks at $r=0.11,0.33$, and $0.76 \mu \mathrm{m}$. The layer below the aircraft shows three peaks at $r=0.11,0.99$, and $6.64 \mu \mathrm{m}$.

\subsubsection{Single scattering albedo}

As noted in Sect. 4.2, retrievals of single scattering are not reliable when the aerosol optical thickness is far less than 0.4 , which is often assumed to be a rough cut-off for single scattering albedo retrievals for sunphotometer retrievals, and often leads to degraded accuracy due to insufficient signal-tonoise. In our case, this is especially true for above the aircraft when the optical thickness is quite low. No doubt, quantitative assessment of errors in the joint inversion scheme would help one interpret significance of the results, but it involves complex analysis.

Figure 7 and Table 2 show the spectral single scattering albedo (SSA) retrieved below and above the aircraft over Mongu, Mexico City, Oklahoma, and Barrow. The SSA 
Table 2. Optical properties retrieved from inversion of CAR and AERONET.

\begin{tabular}{|c|c|c|c|c|c|c|}
\hline$\lambda(\mu \mathrm{m})$ & $\begin{array}{l}\text { SSA } \\
\text { (aboveaircraft) }\end{array}$ & $\begin{array}{l}\text { SSA* } \\
\text { (belowaircraft) }\end{array}$ & $\begin{array}{l}n \\
\text { (aboveaircraft) }\end{array}$ & $\begin{array}{l}n \\
\text { (belowaircraft) }\end{array}$ & $\begin{array}{l}k \\
\text { (aboveaircraft) }\end{array}$ & $\begin{array}{l}k \\
\text { (belowaircraft) }\end{array}$ \\
\hline \multicolumn{7}{|c|}{ Mongu } \\
\hline 0.340 & 0.87 & 0.87 & 1.46 & 1.56 & 0.0285 & 0.0304 \\
\hline 0.381 & 0.86 & 0.86 & 1.43 & 1.56 & 0.0263 & 0.0315 \\
\hline 0.440 & 0.87 & 0.84 & 1.44 & 1.52 & 0.0250 & 0.0347 \\
\hline 0.472 & 0.86 & 0.83 & 1.46 & 1.51 & 0.0253 & 0.0356 \\
\hline 0.670 & 0.86 & 0.74 & 1.48 & 1.46 & 0.0209 & 0.0411 \\
\hline 0.682 & 0.86 & 0.73 & 1.48 & 1.46 & 0.0208 & 0.0411 \\
\hline 0.870 & 0.81 & 0.63 & 1.49 & 1.42 & 0.0227 & 0.0436 \\
\hline 1.036 & 0.77 & 0.59 & 1.49 & 1.40 & 0.0241 & 0.0412 \\
\hline 1.219 & 0.72 & 0.56 & 1.49 & 1.40 & 0.0248 & 0.0394 \\
\hline 1.273 & 0.71 & 0.55 & 1.49 & 1.40 & 0.0245 & 0.0393 \\
\hline \multicolumn{7}{|c|}{ Mexico City } \\
\hline 0.340 & 0.64 & 0.89 & 1.33 & 1.42 & 0.0629 & 0.0196 \\
\hline 0.381 & 0.64 & 0.88 & 1.33 & 1.42 & 0.0556 & 0.0193 \\
\hline 0.440 & 0.65 & 0.88 & 1.33 & 1.43 & 0.0483 & 0.0187 \\
\hline 0.472 & 0.63 & 0.88 & 1.33 & 1.43 & 0.0464 & 0.0186 \\
\hline 0.670 & 0.74 & 0.89 & 1.33 & 1.48 & 0.0182 & 0.0131 \\
\hline 0.682 & 0.74 & 0.89 & 1.33 & 1.48 & 0.0182 & 0.0131 \\
\hline 0.870 & 0.74 & 0.88 & 1.33 & 1.50 & 0.0149 & 0.0113 \\
\hline 1.036 & 0.73 & 0.88 & 1.33 & 1.54 & 0.0159 & 0.0108 \\
\hline 1.219 & 0.72 & 0.85 & 1.33 & 1.54 & 0.0174 & 0.0110 \\
\hline 1.273 & 0.72 & 0.85 & 1.33 & 1.54 & 0.0175 & 0.0110 \\
\hline \multicolumn{7}{|c|}{ ARM SGP (Oklahoma) } \\
\hline 0.340 & 0.91 & 0.76 & 1.43 & 1.37 & 0.0093 & 0.0296 \\
\hline 0.381 & 0.91 & 0.74 & 1.39 & 1.37 & 0.0088 & 0.0296 \\
\hline 0.440 & 0.90 & 0.70 & 1.35 & 1.36 & 0.0085 & 0.0302 \\
\hline 0.472 & 0.89 & 0.69 & 1.36 & 1.36 & 0.0084 & 0.0306 \\
\hline 0.670 & 0.88 & 0.52 & 1.38 & 1.33 & 0.0085 & 0.0449 \\
\hline 0.682 & 0.88 & 0.52 & 1.38 & 1.33 & 0.0084 & 0.0449 \\
\hline 0.870 & 0.86 & 0.46 & 1.38 & 1.33 & 0.0096 & 0.0548 \\
\hline 1.036 & 0.86 & 0.44 & 1.38 & 1.33 & 0.0100 & 0.0577 \\
\hline 1.219 & 0.86 & 0.45 & 1.38 & 1.33 & 0.0096 & 0.0575 \\
\hline 1.273 & 0.86 & 0.45 & 1.38 & 1.33 & 0.0097 & 0.0575 \\
\hline \multicolumn{7}{|c|}{ Elson Lagoon } \\
\hline 0.340 & 0.91 & 0.78 & 1.44 & 1.42 & 0.0111 & 0.0208 \\
\hline 0.381 & 0.91 & 0.78 & 1.43 & 1.42 & 0.0109 & 0.0208 \\
\hline 0.440 & 0.91 & 0.78 & 1.42 & 1.41 & 0.0107 & 0.0211 \\
\hline 0.472 & 0.91 & 0.78 & 1.42 & 1.41 & 0.0106 & 0.0211 \\
\hline 0.670 & 0.91 & 0.78 & 1.41 & 1.39 & 0.0097 & 0.0224 \\
\hline 0.682 & 0.91 & 0.78 & 1.41 & 1.39 & 0.0097 & 0.0224 \\
\hline 0.870 & 0.89 & 0.77 & 1.39 & 1.38 & 0.0126 & 0.0281 \\
\hline 1.036 & 0.87 & 0.78 & 1.41 & 1.39 & 0.0148 & 0.0311 \\
\hline 1.219 & 0.86 & 0.79 & 1.40 & 1.39 & 0.0153 & 0.0309 \\
\hline 1.273 & 0.86 & 0.80 & 1.40 & 1.39 & 0.0154 & 0.0309 \\
\hline
\end{tabular}

* magnitude of uncertainty in SSA is larger for low $\tau_{a}$ (see Sect. 4.2.2)

for Mongu (Fig. 7a) and Oklahoma, bottom layer (Fig. 7c) show a stronger spectral dependence, while there is a weak spectral dependence for Mexico City (layer above aircraft, Fig. 7b), Oklahoma, layer above aircraft (Fig. 7c) and Barrow (Fig. 7d). Higher SSA values (less absorption) are retrieved in the layer above the aircraft in all cases except for Mexico City. The retrieved values are consistent with other studies (e.g., Magi et al., 2007). However, the magnitude of uncertainty in SSA is expected to be large for low aerosol optical depth cases, especially below the plane where surface reflectance is generally much stronger than scattering of aerosol in the backscattering hemisphere. This is discussed in detail in Sect. 2.3.2 and illustrated in the work of Dubovik et al. (2000). Since the retrieval technique insures only the fact that the retrieved combination of all of the pa-
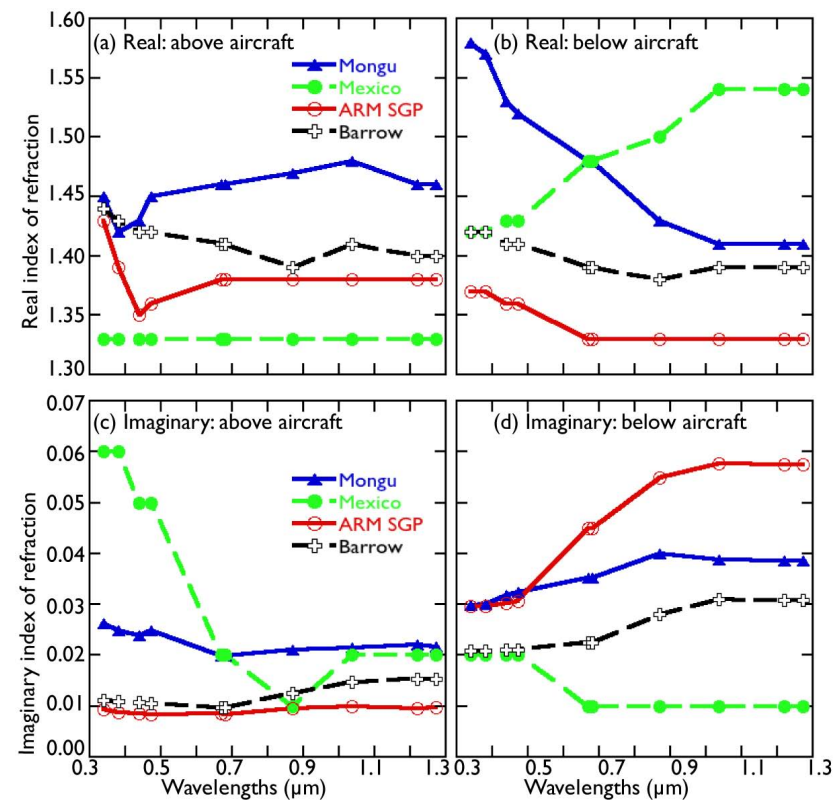

Fig. 8. Real and Imaginary index of refraction retrieved from combined CAR and AERONET measurements taken over Mongu, Zambia on 6 September 2000, Mexico City, Mexico, 6 March 2006, SGP Central Facility, Oklahoma, 24 June 2007 and Elson Lagoon, Barrow, Alaska, 6 April 2008. The index of refraction is separated into two layers above and below the aircraft.

rameters does accurately reproduce the measured radiation field, larger biases in one parameter should not diminish the value of retrieval results, but it will be studied in a follow up study to help develop a better understanding of aerosol absorption (and index of refraction) at lower optical thickness.

\subsubsection{Complex index of refraction}

The retrieval of complex refractive index of refraction is a very difficult task, which sometime requires polarization measurements and even then it is not always possible. The lack of such data in our joint retrieval could lead to degraded accuracy in our retrievals, but it does not diminish the importance of demonstrating the potential of these kind joint retrievals. However, more work is needed and will be pursued in the future.

Figure 8 and Table 2 show retrieved values of complex index of refraction (real and imaginary parts) both above and below the aircraft for Mongu, Mexico City, Oklahoma, and Barrow. Figure $8 \mathrm{a}$ and $\mathrm{b}$ show the real index of refraction for the layers above and below the aircraft, respectively. For the most part, there is a weak spectral dependence of the real part of the complex index of refraction, except in the layer below the aircraft for Mongu and Mexico City. The same is true for the imaginary part of the complex index of refraction, except for Mexico City above the aircraft and Oklahoma below the aircraft. 


\subsubsection{BRF parameters}

Although it is important to check the performance of the inversion method with different BRDF models, we will demonstrate the performance of the inversion using the Coupled Surface-Atmosphere Reflectance (CSAR) model (cf. Rahman et al., 1993a, b). In the future, we will compare performances of different BRDF models.

The CSAR is a three-parameter semi-empirical model based on a product of three functions: (i) a modified Minnaert function (Minnaert, 1941), which is a combination of the view and illumination zenith angles, (ii) a one-term Henyey-Greenstein term $F(g)$, and (iii) a hot spot function simulated by $1+R(G)$. The overall BRF model thus takes the form

$\rho_{s}\left(\theta_{1}, \phi_{1} ; \theta_{2}, \phi_{2}\right)$

$=\rho_{0} k \frac{\cos ^{k-1} \theta_{1} \cos ^{k-1} \theta_{2}}{\left(\cos \theta_{1}+\cos \theta_{2}\right)^{1-k}} F(g)[1+R(G)]$,

where $\rho_{s}$ is the reflectance of a surface illuminated from a direction $\left(\theta_{1}, \phi_{1}\right)$ and observed in a direction $\left(\theta_{2}, \phi_{2}\right)$, and $\rho_{0}$ and $k$ are two empirical parameters representing the intensity of the surface reflectance and the level of surface reflectance anisotropy, respectively. The function $F(g)$, due to Henyey and Greenstein (1941), is defined as

$F(g)=\frac{1-\Theta^{2}}{\left[1+\Theta^{2}-2 \Theta \cos (\pi-g)\right]^{1.5}}$,

where $\Theta$ is the function parameter that controls the relative amount of forward $(0 \leq \Theta \leq 1)$ and backward scattering $(-1 \leq \Theta \leq 0)$. The phase angle $g$ is given by

$\cos g=\cos \theta_{1} \cos \theta_{2}+\sin \theta_{1} \sin \theta_{2} \cos \left(\phi_{1}+\phi_{2}\right)$,

The hot spot is simulated by the function

$1+R(G)=1+\frac{1-\rho_{0}}{[1+G]}$,

where $G$, the geometrical factor, is defined as

$G=\left[\tan ^{2} \theta_{1}+\tan ^{2} \theta_{2}-2 \tan \theta_{1} \tan \theta_{2} \cos \left(\phi_{1}-\phi_{2}\right)\right]^{1 / 2}$.

So the surface bidirectional reflectance is described in terms of three independent parameters: $\rho_{0}, k$, and $\Theta$, with an assumed range of variability defined by $0.001 \leq \rho_{0} \leq 0.99$; $0.1 \leq k \leq 1$, and $-0.5 \leq \Theta \leq 0.5$, respectively. No specific restrictions on spectral dependence of these parameters are assumed other than spectral smoothness constraints. Since retrieved parameters are analyzed in logarithmic space as stated in section 2.4 and the CSAR model parameter $\Theta$ takes negative values (i.e., $-0.5 \leq \Theta \leq 0.5$; Rahman et al., 1993a), a simple transformation in the form $(1+\Theta)$ is used.

Figure 9 shows spectral bidirectional reflectance factors (BRF) in the solar principal plane at selected wavelengths from the CSAR model inversion for Mongu, Mexico City, Oklahoma, and Barrow. The BRF of snow (Barrow) is much

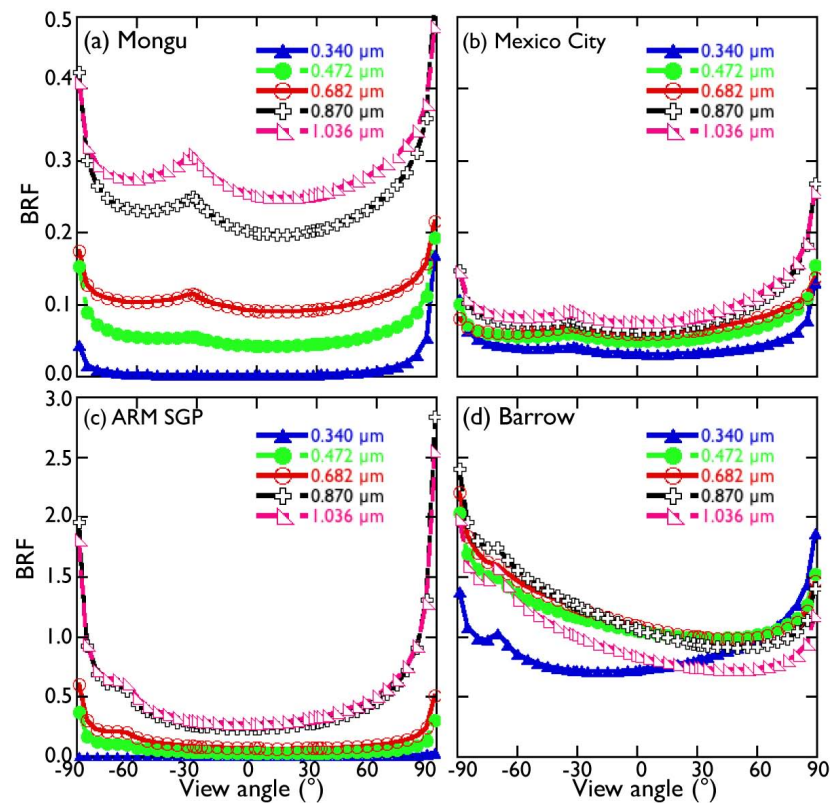

Fig. 9. Spectral bidirectional reflectance factors (BRF) in the solar principal plane for selected wavelengths calculated from CSAR model parameters inverted from combined CAR/AERONET measurements taken over Mongu, Zambia on 6 September 2000, Mexico City, Mexico, 6 March 2006, SGP Central Facility, Oklahoma, 24 June 2007, and Elson Lagoon, Barrow, Alaska, 6 April 2008.

larger than the rest of the surfaces and is the lowest for Oklahoma. Results of BRF for Mongu compare well with previous estimates (Gatebe et al., 2003).

\section{Summary and conclusions}

In this paper, we described a new inversion algorithm for retrieving detailed aerosol optical properties and BRDF parameters from CAR radiance data alone or combined with other datasets such as AERONET. The algorithm is based on the standard AERONET algorithm for retrieving aerosol size distribution, complex index of refraction, and single scattering albedo, but was modified to retrieve aerosol properties in two layers, above and below the aircraft, and parameters of the surface angular reflectance. We tested the robustness of the new algorithm using data from four different locations, Mongu (Zambia), Mexico City (Mexico), ARM Central Facility (Oklahoma, USA), and Elson Lagoon (Barrow, Alaska, USA) from four different fields campaigns: SAFARI 2000, INTEX-B, CLASIC, and ARCTAS, respectively.

A key advantage of this method is the inversion of all available spectral and angular data at the same time, while accounting for the influence of noise in the inversion procedure using statistical optimization. The wide spectral $(0.34-2.30 \mu \mathrm{m})$ and angular range $\left(180^{\circ}\right)$ of the CAR instrument combined with observations from AERONET sun/sky 
radiometer was found to provide sufficient measurement constraints for characterizing aerosol and surface properties with minimal assumptions, which is common in the current retrievals schemes. This approach will enable understanding of the influence of the surface directional effects on aerosol retrievals.

Acknowledgements. This research was supported by the Science Mission Directorate of the National Aeronautics and Space Administration as part of the Radiation Sciences Program under Hal B. Maring and Airborne Science Program under Andrew C. Roberts. Special thanks to Gala Wind and Thomas Arnold for their facilitating of CAR data processing and Rajesh Poudyal for help with Fig. 3. We thank the AERONET project and staff for supporting and providing access to the sunphotometer raw data, and Rick Wagener for establishing and maintaining AERONET sun/sky radiometers at the ARM sites in Oklahoma and Barrow, Alaska. This work was performed under NASA Grant NNX08AF89G.

Edited by: A. Stohl

\section{References}

Abbot, C. G.: The Radiation of the Sun. An extract from the Annual Report of the Smithsonian Institution for 1912, Government Printing Office, Washington DC, USA, 17 pp., 1913.

Abney, W. de W.: Transmission of sunlight through the Earth's atmosphere. Part II. Loss of light at different altitudes, Phil. Trans. Royal Soc. London A, 184, 1-42, 1893.

Ångström, A.: On the atmospheric transmission of sun radiation and on dust in the air, Geograf. Ann. Deut., 11, 156-166, 1929.

Ångström, A.: The parameters of atmospheric turbidity, Tellus, 16, 64-75, 1964.

Bouguer, P.: Traité d'Optique sur la gradation de la lumiere: ouvrage posthume de J. Bouguer, de l'Academis Royale des Sciences, \& publié par M. l'Abbé de la Caille, de la meme Académie, \&c English translation: Optical treatise on the gradation of light, posthumous work of Mr. Pierre Bouguer of the Royal Academy of Sciences, etc. and published by the Abbé de la Caille of the same Academy, etc.; with introduction and notes by Middleton, W. E. (1961), Pierre Bouguer's Optical Treatise on Gradation of Light, University of Toronto Press, Toronto, Canada, 241 pp., 1760.

Chandrasekhar, S.: Radiative Transfer, 393 pp., Dover Publications, Inc., New York, 1960.

Cox, C., and Munk, W.: The measurements of the roughness of the sea surface from photographs of the sun's glitter, J. Opt. Soc. Amer., 44, 838-850, 1954a.

Cox, C., and Munk, W.: Statistics of the sea surface derived from sun glitter, J. Mar. Res., 13, 198-227, 1954b.

Deepak, A. and M.A. Box: Forward scattering corrections for optical extinction measurements in aerosol media, 1: monodispersions, Appl. Opt, 17, 2900-2908, 1978.

Deirmendjian, D., and Sekera, Z.: Atmospheric and the transmission of ultraviolet sunlight, J. Opt. Soc. Amer., 46, 565-571, 1956.

Deuzé, J. L., Breon, F. M., Deschamps, P. Y., Devaux, C., Herman, M., Podaire, A., and Roujean, J. L.: Analysis of the POLDER (Polarization and Directionality of Earth's Reflectances) airborne instrument observations over land surfaces, Remote Sens. Environ., 45, 137-154, 1993.

Diner, D. J., Abdou, W. A., Ackerman, T. P., Crean, K., Gordon, H. R., Kahn, R. A., Martonchik, J. V., McMuldroch, S., Paradise, S. R., Pinty, B., Verstraete, M. M., Wang, M., and West, R. A.: MISR level 2 aerosol retrieval algorithm theoretical basis, JPL D-11400, Rev. G, Jet Propul. Lab., Calif. Inst. of Technol., Pasadena, CA, USA, online available at: eospso.gsfc.nasa.gov/ eos_homepage/for_scientists/atbd, 2008.

Dubovik, O. and, King, M. D.: A flexible inversion algorithm for retrieval of aerosol optical properties from sun and sky radiance measurements, J. Geophys. Res., 105, 20673-20696, 2000.

Dubovik, O., Smirnov, A., Holben, B. N., King, M. D., Kaufman, Y. J., Eck, T. F., and Slutsker, I.: Accuracy assessment of aerosol optical properties retrieved from Aerosol Robotic Network (AERONET) sun and sky radiance measurements, J. Geophys. Res., 105, 9791-9806, 2000.

Dubovik, O, Holben, B., Eck, T. F., Smirnov, A., Kaufman, Y. J., King, M. D., Tanré, D., and Slutsker, I.: Variability of absorption and optical properties of key aerosol types observed in worldwide locations, J. Atmos. Sci., 59, 590-608, 2002.

Dubovik, O.: Optimization of numerical inversion in photopolarimetric remote sensing, in Photopolarimetry in Remote Sensing (G. Videen, Y. Yatskiv and M. Mishchenko, Eds.), Kluwer Academic Publishers, Dordrecht, Netherlands, 65-106, 2004.

Dubovik, O., Sinyuk, A., Lapyonok, T., Holben, B. N., Mishchenko, M., Yang, P., Eck, T. F., Volten, H., Muñoz, O., Veihelmann, B., van der Zande, W. J., Léon, J. F., Sorokin, M., and Slutsker, I.: Application of spheroid models to account for aerosol particle nonsphericity in remote sensing of desert dust, J. Geophys. Res., 111, D11208, doi:10.1029/2005JD006619, 2006.

Eck, T. F., Holben, B. N., Ward, D. E., Mukelabai, M. M., Dubovik, O., Smirnov, A., Schafer, J. S., Hsu, N. C., Piketh, S. J., Queface, A., Le Roux, J., Swap, R. J., and Slutsker, I.: Variability of biomass burning aerosol optical characteristics in southern Africa during the SAFARI 2000 dry season campaign and a comparison of single scattering albedo estimates from radiometric measurements, J. Geophy. Res., 108, 8477, doi:10.1029/2002JD002321, 2003.

Gatebe, C. K., King, M. D., Platnick, S., Arnold, G. T., Vermote, E. F., and Schmid, B.: Airborne spectral measurements of surface-atmosphere anisotropy for several surfaces and ecosystems over southern Africa, J. Geophys. Res., 108, 8489, doi:10.1029/2002JD002397, 2003.

Gatebe, C. K., Butler, J. M., Cooper, J. W., Kowalewski, M., and King, M. D.: Characterization of errors in the use of integratingsphere systems in the calibration of scanning radiometers, Appl. Opt., 7640-7651, 2007.

Griggs, M.: Measurement of atmospheric aerosol optical thickness over water using ERTS-1 data, J. Air Pollut. Contr. Assoc., 25, 622-626, 1975.

Hale, G. M. and Querry, M. R.: Optical constants of water in the $200 \mathrm{~nm}$ to $200 \mu \mathrm{m}$ wavelength region, Appl. Opt., 12, 555-563, 1973.

Henyey, R. G. and Greenstein, T. L.: Diffuse radiation in the galaxy, Astrophys. J., 93, 70-83, 1941.

Herman B. N., and Yarger, D. N.: Some effects of multiple scattering on heating rates in the ozone layer, J. Atmos. Sci., 23, 320-324, 1966. 
Herman, B. M., Browning, S. R., and Curran, R. J.: The effect of atmospheric aerosols on scattered sunlight, J. Atmos. Sci., 28, 419-428, 1971.

Herman, J. P., Bhartia, P. K., Torres, O., Hsu, C., Seftor, C., and Celarier, E.: Global distribution of UV-absorbing aerosols from Nimbus 7/TOMS data, J. Geophys. Res. 102, 16911-16922, 1997.

Holben, B. N., Eck, T. F., Slutsker, I., Tanré, D., Buis, J. P., Setzer, A., Vermote, E., Reagan, J. A., Kaufman, Y. J., Nakajima, T., Lavenu, F., Jankowiak, I., and Smirnov, A.: AERONET-A federated instrument network and data archive for aerosol characterization, Remote Sens. Environ. 66, 1-16, 1998.

Hsu, C. N., Tsay, S. C., King, M. D., and Herman, J. R.: Aerosol properties over bright-reflecting source regions, IEEE T. Geosci. Remote Sens., 42, 557-569, 2004.

Kaufman, Y. J., Tanré, D., Gordon, H. R., Nakajima, T., Lenoble, J., Frouin, R., Grassl, H., Herman, B. M., King, M. D., and Teillet, P. M.: Passive remote sensing of tropospheric aerosol and atmospheric correction for the aerosol effects, J. Geophys. Res., 102, 16815-16830, 1997.

King, M. D., Byrne, D. M., Herman, B. M., and Reagan, J. A.: Aerosol size distributions obtained by inversion of spectral optical depth measurements, J. Atmos. Sci., 35, 2153-2167, 1978.

King, M. D.: Sensitivity of constrained linear inversions to the selection of the Lagrange multiplier, J. Atmos. Sci., 39, 13561369, 1982.

King, M. D., Strange, M. G., Leone, P., and Blaine, L. R.: Multiwavelength scanning radiometer for airborne measurements of scattered radiation within clouds, J. Atmos. Ocean. Technol., 3, 513-522, 1986.

King, M. D., Kaufman, Y. J., Tanré, D., and Nakajima, T.: Remote sensing of aerosols from space: Past, present, and future, Bull. Amer. Meteor. Soc., 80, 2229-2259, 1999.

Lambert, J. H.: Photometria sive de mensura et gradibus, luminis, colorum et umbrae, (English translation: Photometry, or, on the measure and gradations of light, colors and shade; with introductory monograph and notes by David L. DiLaura, 2001, The Illuminating Engineering Society of North America, New York, USA,) 1760.

Lenoble, J. (ed.): Radiative transfer in scattering and absorbing atmospheres: standard computational procedures, Deepak Publishing, Hampton, Virginia, USA, 300 pp., 1985.

Lucht, W., Schaaf, C. B., and Strahler, A. H.: An algorithm for the retrieval of albedo from space using semi-empirical BRDF models, IEEE T. Geosci. Remote Sens., 38, 977-967, 2000.

Magi, B. I., Fu, Q., and Redemann, J.: A methodology to retrieve self-consistent aerosol optical properties using common aircraft measurements, J. Geophys. Res., 112, D24S12, doi:10.1029/2006JD008312, 2007.

Minnaert, M.: The reciprocity principle in lunar photometry, Astrophys. J., 93, 403-410, 1941.

Mishchenko, M. I. and Travis, L. D.: Satellite retrieval of aerosol properties over the ocean using polarization as well as intensity of reflected sunlight, J. Geophys. Res., 102, 16989-17013, 1997.

Nakajima, T. and Tanaka, M.: Effect of wind-generated waves on the transfer of solar radiation in the atmosphere-ocean system, J. Quant. Spectrosc. Radiat. Transfer, 29, 521-537, 1983.

Nakajima, T. and Tanaka, M.: Algorithms for radiative intensity calculations in moderately thick atmospheres using a truncation approximation, J. Quant. Spectrosc. Radiat. T., 40, 51-69, 1988.

Nakajima, T., Tanaka, M., and Yamauchi, T.: Retrieval of the optical properties of aerosols from aureole and extinction data, Appl. Opt., 22, 2951-2959, 1983.

Nakajima, T., Tonna, G., Rao, R., Boi, P., Kaufman, Y., and Holben, B.: Use of sky brightness measurements from ground for remote sensing of particulate polydispersions, Appl. Opt., 35, 2672-2686, 1996.

Phillips, D. L.: A technique for the numerical solution of certain integral equations of the first kind, J. Assoc. Comput. Mach., 9, 84-97, 1962.

Pilewskie, P., Pommier, J., Bergstrom, R., Gore, W., Howard, S., Rabbette, M., Schmid, B., Hobbs, P. V., and Tsay, S. C.: Solar spectral radiative forcing during the Southern African Regional Science Initiative, J. Geophy. Res., 108, 8486, doi:10.1029/2002JD002411, 2003.

Rahman, H., Pinty, B., and Verstraete, M. M.: Coupled surfaceatmosphere reflectance (CSAR) model 1. Model description and inversion on synthetic data, J. Geophys. Res., 98, 20779-20789, 1993a.

Rahman, H., Pinty, B., and Verstraete, M. M.: Coupled surfaceatmosphere reflectance (CSAR) model 2. Semi-empirical surface model usable with NOAA Advanced Very High Resolution Radiometer data, J. Geophys. Res., 98, 20791-20801, 1993b.

Russell, P. B., Livingston, J. M., Hignett, P., Kinne, S., Wong, J., and Hobbs, P. V.: Aerosol-induced radiative flux changes off the United States Mid-Atlantic coast: Comparison of values calculated from sunphotometer and in situ data with those measured by airborne pyranometer, J. Geophys. Res., 104, 2289-2307, 1999.

Shaw, G. E., Reagan, J. A., and Herman, B. M.: Investigations of atmospheric extinction using direct solar radiation measurements made with a multiple wavelength radiometer, J. Appl. Meteor., 12, 374-380, 1973.

Shaw, G. E.: Inversion of optical scattering and spectral extinction measurements to recover aerosol size spectra, Appl. Opt., 18, 988-993, 1979.

Tanré, D., Kaufman, Y. J., Herman, M., and Mattoo, S.: Remote sensing of aerosol properties over oceans using the MODIS/EOS spectral radiances, J. Geophys. Res., 102, 16971-16988, 1997.

Sinyuk, A., Dubovik, O., Holben, B. N., Eck, T. F., Breon, F. M., Martonchik, J., Kahn, R., Diner, D. J., Vermote, E. F., Roger, J. C., Lapyonok, T., and Slutsker, I.: Simultaneous retrieval of aerosol and surface properties from a combination of AERONET and satellite data, Remote Sens. Environ, 107, 90-108, 2007.

Thomas, G. E. and Stamnes, K., Radiative transfer in the atmosphere and ocean, Cambridge Univ. Press, New York, USA, 517 pp., 1999.

Twomey, S.: On the numerical solution of Fredholm integral equations of the first kind by the inversion of the linear system produced by quadrature, J. Assoc. Comput. Mach., 10, 97-101, 1963.

Volz, F. E.: Photometer mit Selen-Photoelement zur spektralen Messung der Sonnenstrahlung und zur Bestimmung der Wellenlängenabhängigkeit der Dunsttrübung, Arch. Meteorolo. Geophys. Bioklim., B10, 100-131, 1959.

Wanner, W., Li, X., and Strahler, A. H.: On the derivation of kernels for kernel-driven models of bidirectional reflectance, J. Geophys. Res., 100, 21077-21089, 1995. 
Wanner, W., Strahler, A. H., Hu, B., Lewis, P., Muller, J., Li, X., Schaaf, C. B., and Barnsley, M.: Global retrieval of bidirectional reflectance and albedo over land from EOS MODIS and MISR data: Theory and algorithm, J. Geophys. Res., 102, 17143-17161, 1997.
Yamamoto, G. and Tanaka, M.: Determination of aerosol size distribution from spectral attenuation measurements, Appl. Opt., 8, 447-453, 1969. 